\title{
LA PARTICIPACIÓN DE LAS COMUNIDADES AUTÓNOMAS EN LA ELECCIÓN POR EL SENADO DE LOS MAGISTRADOS CONSTITUCIONALES
}

\author{
JUAN FRANCISCO SÁNCHEZ BARRILAO \\ Profesor Titular de Derecho Constitucional \\ Universidad de Granada
}

\author{
SUMARIO \\ I. Introducción. \\ II. La elección por el Senado de cuatro \\ Magistrados constitucionales. \\ III. Comentario de las Sentencias del \\ Tribunal Constitucional 49/2008 \\ y 101/2008. \\ IV. Consideraciones finales.
}

\section{INTRODUCCIÓN}

El precedente de la participación de las Regiones en la composición del Tribunal de Garantías Constitucionales de la II República ${ }^{1}$ encontró escaso eco durante el proceso constituyente de 1978, no siendo aceptadas las enmiendas presentadas por las minorías nacionalistas al respecto de una posible participación de las, en aquel entonces, futuras Comunidades Autónomas en el nuevo Tribunal Constitucional español (art. 159.1 CE)². Pero que ello fuera así en aquel momento, no lleva sin más a que tras la consolidación y el desarrollo de las Comunidades Autónomas no quepa replantearse tal participación.

1 Vid. R. M. Ruzz Lapeña, El Tribunal de Garantias Constitucionales en la II República, BOSCH, Barcelona, 1982, págs. 162 a 175.

2 Con carácter general, cfr. G. VALENCIA MarTín, "Artículo 5", en AAVV Comentarios a la Ley Orgánica del Tribunal Constitucional, J. L. Requejo Pagés (coord.), Tribunal Constitucional/Boletín Oficial del Estado, Madrid, 2001, págs. 148 y 149. 
Ya en 2001 P. Cruz Villalón (en su condición de Presidente del Tribunal Constitucional) afirmaría, bajo la premisa de que toda renovación del Tribunal Constitucional puede considerarse un "momento de renovación del consenso constitucional", cómo cualquier forma de expansión del pluralismo en el seno del Tribunal Constitucional debería ser bien recibida; y en esta línea, que el Senado quepa asumir y liderar una "sensibilidad autonómica" en relación con la composición del Constitucional, aunque apartándose de cualquier idea de representación de los Magistrados ${ }^{3}$.

Considerada la preponderancia parlamentaria en la elección de los Magistrados constitucionales como una de las claves de la legitimación democrática del Tribunal Constitucional ${ }^{4}$, cabe asimismo afirmar la conveniencia en el seno del Tribunal de una composición más perceptiva a las distintas sensibilidades autonómicas que hoy concurren sobre el Estado autonómico, a fin de potenciar una mayor integración de éstas en la resolución de los conflictos territoriales. Y así que, especialmente tras el impulso que para el Estado autonómico han supuesto las últimas reformas estatutarias acaecidas ${ }^{5}$, nos resulte adecuado instrumentar a través del Senado la actual integración territorial del Estado español en relación a la plural composición del Tribunal Constitucional ${ }^{6}$. Posibilidad que, abriéndose paso progresivamente ${ }^{7}$, finalmente se ha materializado a nivel normativo con ocasión de las reformas de los artículos 16.1 de la Ley Orgánica del Tribunal Constitucional (LO 6/2007, de 24 de mayo) y 184.7 del Reglamento del Senado (Reforma de 21 de no-

3 P. CRuZ Villalón, «Discurso pronunciado por el Presidente del Tribunal Constitucional con ocasión de la renovación parcial del Tribunal (7 de noviembre de 2001)", www.tribunal constitucional.es/memorias/2001/memo01_anexo05.html (03/10/2008).

4 Así, P. J. GonzÁlez-Trevijano, El Tribunal Constitucional, Aranzadi, Elcano, 2000, págs. 72 y 73.

$5 \mathrm{Al}$ respecto de éstas, vid. F. BALAguer CALlejón, "Las últimas reformas estatutarias", junto a G. Cámara Villar, J. F. López Aguilar, M. L. Balaguer Callejón, J. A. Montilla Martos, Manual de Derecho Constitucional (I), F. Balaguer Callejón (coord.), 3. ${ }^{a}$ ed., Madrid, Tecnos, 2008, págs. 364 y ss.

6 J. F. Sánchez Barrilao, "Sobre el interés de las Comunidades Autónomas en la composición del Tribunal Constitucional", en AAVV El Estado Autonómico. Integración, solidaridad y diversidad (I), J. M. Vidal Beltrán y M. A. García Herrera (coords.), Colex/INAP, Madrid, 2005, págs. 155 y ss.

7 A nivel doctrinal cfr., por ejemplo: E. AJA - C. VIVER PI-SunYer, «Valoración de 25 años de autonomía", Revista Española de Derecho Constitucional, núm. 69, 2003, págs. 110 y 112; G. CÁMARA VILLAR, “El principio y las relaciones de colaboración entre el Estado y las Comunidades Autónomas", Revista de Derecho Constitucional Europeo, núm. 1, 2004, pág. 217; y J. F. SÁnchez BARRILAO, ibidem. Y aunque matizadamente, vid.: E. Espín TeMPLADO, "Art. 16", en AAVV Comentarios a la Ley Orgánica del Tribunal Constitucional... cit., págs. 296 y 297; S. A. ROURA, Federalismo y justicia constitucional en la Constitución española de 1978 (El Tribunal Constitucional y las Comunidades Autónomas), Biblioteca Nueva, Madrid, 2003, págs. 201 y ss.; o A. Ruzz Robledo, "Veinticinco años de Estado Autonómico", Revista de Derecho Político, núms. 58-59, 2003-2004, pág. 723.

8 Todavía durante la tramitación de la reforma de la LOTC, vid. J. URÍAs, "Nota sobre los conflictos territoriales ante la reforma de la LOTC", en AAVV La reforma del Tribunal Constitucional (Actas del V Congreso de la Asociación de Constitucionalistas de España), P. Pérez 
viembre de 2007) ${ }^{8}$, y al tiempo, asimismo, al amparo de las Sentencias del Tribunal Constitucional 49/2008, de 9 de abril, y 101/2008, de 24 de julio de 2008 , las cuales han resuelto dos recursos de inconstitucionalidad relativos a sendas reformas 9 .

Es a estos efectos que dediquemos las siguientes páginas a las citadas Sentencias; pero antes, deteniéndonos, aun someramente, en el procedimiento de elección por el Senado de cuatro de los doce Magistrados constitucionales tanto en relación al estadio previo de las recientes reformas de la Ley Orgánica del Tribunal Constitucional (en adelante LOTC) y del Reglamento del Senado (en adelante RS), como al mismo una vez llevadas a cabo, a fin de comprobar cuál sea el cambio efectivamente alcanzado. Apuntadas tales reformas, estaremos entonces en disposición de presentar y comentar las Sentencias 49/2008 y 101/2008, terminando con una serie de consideraciones críticas al respecto de ellas, como de la jurisdicción constitucional hoy en España.

\section{LA ELECCIÓN POR EL SENADO DE CUATRO MAGISTRADOS CONSTITUCIONALES}

El artículo 159.1 de la Constitución fija en doce el número de Magistrados constitucionales, siendo nombrados por el Rey. De éstos, el Congreso de los Diputados elige cuatro por mayoría de tres cuartos de sus miembros, y otros cuatro el Senado con igual mayoría; y de los otros cuatro, dos el Gobierno, y dos el Consejo General del Poder Judicial ${ }^{10}$. Es así que el nombramiento real

Tremps (Corrd.), Tirant lo Blanch, Valencia, 2007, págs. 933 y 934. Y ya, tras la aprobación de la referida reforma cfr., expresamente a favor de la misma, F. BALAGuer Callejón, G. CÁmara VILLAR,Y L. F. MEDina REY, La nueva Ley Orgánica del Tribunal Constitucional, F. Balaguer Callejón (coord.), Tecnos, Madrid, 2008, págs. 46 y 47. También, vid. M. CARrillo, "La reforma de la jurisdicción constitucional: la necesaria racionalización de un órgano constitucional en crisis", págs. 73-77, G. FERnÁndez FARreres, "La reforma de la Ley Orgánica del Tribunal Constitucional (Comentario a la Ley Orgánica 6/2007, de 24 de mayo)", págs. 174-179, ambos junto a E. Fossas EsPADALER - A. GARRORENA MORALES en Hacia una nueva jurisdicción constitucional (Estudios sobre la ley 6/2007, de 24 de mayo de reforma de la LOTC), M. Carrillo (coord.), Tirant lo Blanch, Valencia, 2008.

$9 \mathrm{Al}$ respecto, vid. los comentarios de: M. CARRILLO, "Comentario a la STC 49/2008, de 9 de abril", en AAVV Hacia una nueva justicia constitucional... cit., págs. 261 y ss.; A. L. SANZ PÉREZ, "Comentario a la STC 49/2008. Las fuentes del Derecho Parlamentario y el Senado", Repertorio Aranzadi del Tribunal Constitucional, núm. 9, 2008, págs. 13-28, y “STC 101/2008: La nueva relación entre el Senado y los Parlamentos Autonómicos", asimismo en Repertorio Aranzadi del Tribunal Constitucional, núm. 13, 2008, págs. 13-31; también, I. TORRES Muro, "La reforma de la Ley Orgánica del Tribunal Constitucional y del Reglamento del Senado, puesta a prueba (SSTC 49/2008, de 9 de abril y 101/2008, de 24 de julio)", Revista General de Derecho Constitucional, núm. 6, 2008, en http://www.iustel.com/v2/revistas (20/12/2008).

10 Para una primera aproximación a la composición del Tribunal Constitucional español, F. FERNÁNDEZ SEGADO, "Artículo 159. La composición del Tribunal Constitucional", en AAVV Comentarios a la Constitución española de 1978 (XII), O. Alzaga Villaamil (dir.), Cortes Generales-EDERSA, Madrid, 1999, págs. 71 y ss. 
quede sujeto a la propuesta de órganos con legitimación democrática (art. 1.2 y $3 \mathrm{CE}$ ), y que además predomine la de las Cortes Generales, dada su central posición en el sistema político español (arts. 66 y ss. CE) ${ }^{11}$.

Respecto a su concreta procedimentalización ante el Congreso de los Diputados, y en conformidad con el Reglamento de éste, la elección corresponde al Pleno de la Cámara (art. 204.1 RC). A este fin, los grupos parlamentarios pueden proponer hasta un máximo de cuatro candidatos, pudiendo intervenir en su postulación un representante del grupo proponente antes de la votación (art. $204.2 \mathrm{RC})^{12}$; y en cuanto a la votación, los Diputados pueden escribir en la papeleta hasta cuatro nombres (art. 204.3 $\mathrm{RC}$ ), siendo elegidos los cuatro candidatos que obtengan más votos, siempre que alcancen los tres quintos de los votos de los miembros del Congreso (art. 204.4 RC) $)^{13}$.

\section{II.A. EL MARCO NORMATIVO PREVIO A LAS REFORMAS}

En relación con los Magistrados constitucionales elegidos por el Senado, y antes de las referidas reformas, correspondía también al Pleno su decisión, previo informe de la Comisión de Nombramientos sobre las candidaturas presentadas por los grupos parlamentarios (arts. 184 a 186 RS) ${ }^{14}$; y así, que la condición territorial del Senado (art. 69.1 CE) no tuviera ningún reflejo al respecto. No en vano, localizándose ciertas funciones del Senado concernientes al Estado autonómico en la Comisión General de las Comunidades Autónomas (art. 56 RS), ni siquiera dicha Comisión intervenía en la propuesta en cuestión.

Ahora bien, el panorama normativo descrito no impedía por sí una hipotética influencia de las Comunidades Autónomas en la elección de los Magistrados del Tribunal Constitucional, en particular a la vista de la singular proyección del sistema de partidos en España respecto a partidos regionalistas y nacionalistas en el Congreso de los Diputados y en el Senado, y el rol que en los mismos pueden desarrollar (especialmente, en caso de coalición o apoyo gubernamental). Sin embargo, y al amparo de las mayorías requeridas, y según han sido éstas tradicionalmente acordadas entre los dos partidos con

11 Cfr. P. Bon, "Espagne”, Annuaire International de Justice Constitutionnelle, 1988, págs. 118 y 119 .

12 A tales efectos, téngase en cuenta también la intervención de la Comisión Consultiva de Nombramientos del Congreso de los Diputados, conforme Resolución de la Presidencia del Congreso de 25 de mayo de 2000.

13 De otra parte, el art. 204.5 y 6 del RC establece diversas normas para el supuesto en que sea necesaria la repetición de las referidas votaciones, por falta de mayoría o por empate.

$14 \mathrm{El}$ procedimiento de propuesta de los Magistrados constitucionales en el Senado era así similar al apuntado en el Congreso, a salvo de la expresa intervención previa de la Comisión de Nombramientos y el informe que ésta hacía sobre la idoneidad de los candidatos para su sucesiva votación en el Pleno del Senado; también, resultaba relevante la posibilidad de comparecencia de los candidatos ante la Comisión. 
mayor número de escaños en las Cortes Generales (art. 159.1 CE), tal posibilidad de intervención de las Autonomías en la elección de los Magistrados constitucionales se ha visto reducida a circunstancias coyunturales, en tanto que los votos positivos de respectivos partidos nacionalistas o regionalistas resultaran necesarios para la formación de dichas mayorías ${ }^{15}$.

\section{II.B. Algunas PROPUESTAS LEGISLATIVAS Y ESTATUTARIAS DE REFORMA DE ESTE PROCESO DE ELECCIÓN}

En este contexto, el Parlamento de Cataluña acordó ya presentar a la Mesa del Congreso de los Diputados una proposición de ley por la que se modificara la LOTC (Resolución 1416/VI), a fin de que los Magistrados nominados a propuesta del Senado lo fueran en representación de las Comunidades Autónomas (29 de mayo de 2002) ${ }^{16}$; y asimismo, al tiempo, el Grupo Parlamentario Catalán en el Senado de Convergència $i$ Unió presentó la Proposición de ley 622/000002 orgánica de modificación de la mencionada LOTC (de 13 de abril de 2004), a tenor de la cual los Magistrados elegidos por el Senado serían designados en representación de las Comunidades Autónomas, a instancia de la Comisión General de las Comunidades Autónomas, y previa consulta a las Asambleas legislativas de aquéllas ${ }^{17}$.

15 En tal sentido, sólo una vez se ha elegido un Magistrado cuya candidatura fuera presentada por partidos regionalistas y nacionalistas (Jesús Leguina Villa, propuesto en 1996 por el Congreso de los Diputados, y bajo la iniciativa conjunta del Partido Socialista Obrero Español, el Partido Nacionalista Vasco y el Grupo Parlamentario Mixto), siendo la regla general, por tanto, que los candidatos al Tribunal vinieran siendo elegidos en el área de los dos partidos con mayor representación parlamentaria.

16 «Els magistrats proposats pel Senat han d'ésser designats en representació de les comunitats autònomes, a proposta de la Comissió General de les Autonomies, amb la consulta prèvia a les assemblees legislatives de les comunitats autònomes o, si n'hi ha alguna de dissolta, a l'òrgan collegiat de govern, d'accord amb el que estableixi la llei pròpia de cada comunitat".

17 “Los magistrados propuestos por el Senado serán designados en representación de las comunidades autónomas, a propuesta de la Comisión General de las Autonomías, previa consulta a las asambleas legislativas de las Comunidades Autónomas o, de haber alguna disuelta, al órgano colegiado de gobierno, de acuerdo con lo establezca la Ley propia de cada Comunidad, (propuesta de reforma de art. 16.1 LOTC). Ambas propuestas legislativas planteaban varios problemas de constitucionalidad, cuales son: el afectar a la reserva reglamentaria del Senado [art. $72.1 \mathrm{CE}$, en cuanto que concurrente con la de ley orgánica (en general, art. $81 \mathrm{CE}$, y la específica de LOTC conforme art. $165 \mathrm{CE}$ ), y no prevista por las propias reforma legales comentadas]; y la genérica dimensión representativa que suponen, incompatible con la condición de independencia e imparcialidad que la Constitución exige y garantiza de los miembros del Tribunal Constitucional (art. 159.4 y 5 CE). Otra cuestión sería la inconstitucionalidad del alcance de la participación misma de las Comunidades, como la del grado de sujeción del Senado a ella (como al tiempo venga a darse a la vista de las SSTC $49 / 2008$ y 101/2008), lo que en tal momento no se plantearía ante la falta de una concreta propuesta de regulación procedimental de todo ello en el seno del Senado. 
De otra parte, y en el marco de las recientes reformas estatutarias ${ }^{18}$, se llega, en el ámbito de las propuestas relativas al Estatuto catalán ${ }^{19}$, al actual artículo 180 de la vigente Ley Orgánica 6/2006, de 19 de julio, de reforma del Estatuto de Autonomía de Cataluña, conforme al cual: "La Generalitat participa en los procesos de designación de Magistrados del Tribunal Constitucional y de miembros del Consejo General del Poder Judicial, en los términos que dispongan las leyes, o, en su caso, el ordenamiento parlamentario". Y en la senda del nuevo Estatuto catalán, se arriba asimismo a los artículos 224 de la Ley Orgánica 2/2007, de 19 de marzo, de reforma del Estatuto de Autonomía para Andalucía, 89.4 de la Ley Orgánica 5/2007, de 20 de abril, de reforma del Estatuto de Autonomía de Aragón, y 58.2.d de la Ley Orgánica 14/2007, de 30 de noviembre, de reforma del Estatuto de Autonomía de Castilla y León; éstos, sin embargo, prevén una mera participación abstracta de las respectivas Comunidades Autónomas en los procesos de designación de los órganos constitucionales, sin referencia expresa al Tribunal Constitucional, y en los términos que dispongan la normativa estatal al respecto ${ }^{20}$.

18 Y dejando al margen la "Propuesta de Estatuto Político de la Comunidad de Euskadi" [presentada por el Lehendakari como reforma estatutaria en la Comunidad Autónoma del País Vasco (Ajuria-Enea, 25 de octubre de 2003), y ulteriormente aprobada por el Parlamento Vasco (30 de diciembre de 2004), finalmente tal propuesta no sería admitida por el Congreso de los Diputados (1 de febrero de 2005)], la cual preveía [al amparo de un bipotético pacto político del País Vasco con el Estado español y su configuración como Comunidad "libremente asociada" a éste (arts. 1 y 12), y desde una más específica idea de representación], nada más y nada menos, que un concreto "Tribunal de Conflicto Euskadi-Estado" a modo de Sala Especial del Tribunal Constitucional (art. 16), y formado por seis Magistrados: tres, a designar por el Tribunal Constitucional en Pleno y a propuesta del Senado (entre los Magistrados que se integraran en el propio Tribunal), y los otros tres restantes a propuesta del Parlamento Vasco (entre juristas vascos).

19 Al respecto, el Institut D'Estudis Autonòmics, en su "Informe sobre la Reforma de L'Estatut" catalán (y a la sombra del déficit que según éste suponía la falta de participación de las Comunidades Autónomas en la designación de los miembros del Tribunal Constitucional), postulaba mecanismos de relación entre el Estado y la Comunidad Autónoma de Cataluña a fin de fomentar la participación de ésta en la vida política estatal, y en especial la designación, a través del Senado, de los Magistrados constitucionales [www10.gencat.net/drep_epc/recursos/iea5.pdf, págs. 29, 50, 51, 141, 142, 143 y 144 (14/10/2004)]. Asimismo, vid. las diversas propuestas de los partidos catalanes en sede parlamentaria al respecto: la del Partit del Socialistes de Catalunya-Ciutadans pel Canvi, "Bases per a l'Elaboració de l'Estatut de Catalunya" [www.parlamentcat.net/porteso/estatut/bases_estatut_soc.pdf (14/10/2004)]; la de Convergència i Unió, "Bases per a un nuo Estatut de Catalunya" [www.parlament-cat.net/porteso/estatut/bases_estatut_ciu.pdf (14/10/2004)]; la de Iniciativa per Catalunya Verds, "Bases per a la Reforma Constitucional i Estatutària" ["Una proposta des del federalisme pluralista i la radicalitat democràtica. Un procés de participació social per a l'elaboració d'un nou Estatut", www.parlament-cat.net/porteso/estatut/ bases_estatut_icu.pdf (14/10/2004)]; y la de Esquerra Republicana de Catalunya, "Constituciò de l'Estat Lliure de Catalunya" [www.parlament-cat.net/porteso/estatut/bases_estatut_erc.pdf $(14 / 10 / 2004)]$.

20 Respectivamente, art. 224 LO 2/2007: «La Junta de Andalucía participa en los procesos de designación de los órganos constitucionales en los términos que dispongan las leyes o, en su caso, el ordenamiento parlamentario". Art. 89.4 LO 5/2007: "La Comunidad Autónoma participará en los procesos de designación de los miembros de las instituciones, organismos y empresas públicas del Estado con el alcance y en los términos establecidos por la legislación estatal». Y art. 58.2.d LO 14/2007: “La Comunidad, de acuerdo con lo establecido en el presente Estatuto y en la 
No obstante, tanto la reforma estatutaria catalana, como la andaluza, la aragonesa y la castellano-leonesa, aunque prevén (expresa o implícitamente) la participación de las respectivas Comunidades Autónomas en la composición del Tribunal Constitucional, se apartan de cualquier idea de representación a dichos efectos; al contrario, lo que buscan es integrarse en la voluntad estatal a la hora de conformar la designación de sus miembros. Otra cosa es la dificultad constitucional que supone, especialmente en relación con el nuevo Estatuto de Cataluña (por su carácter expreso), la reserva reglamentaria del Senado (art. 72.1 CE) y de ley orgánica respecto al Tribunal Constitucional (en general art. $81 \mathrm{CE}$, y la específica de LOTC según art. 165 $\mathrm{CE})$; mas esto, sin perjuicio de que tal intrusión no afecte a la validez de dichas previsiones estatutarias, quedando en el ámbito de la mera eficacia normativa en tanto y en cuanto no exista oportuno y adecuado desarrollo normativo conforme a las respectivas reservas reglamentaria-parlamentaria y legal-orgánica ${ }^{21}$.

\section{II.C. LA REFORMa de la Ley Orgánica del Tribunal Constitucional Y DEL REglamento DEl SENAdo}

Las previsiones estatutarias anteriormente señaladas han encontrado, con todo, desarrollo normativo estatal con ocasión de la Ley Orgánica 6/2007, de 24 de mayo, por la que se modifica la LOTC 2/1979, de 3 de octubre, y en virtud de la cual se añade al artículo 16.1 un segundo párrafo (art. único, apartado $6^{\circ}$, LO 6/2007) ${ }^{22}$, y la reforma del RS (de 3 de mayo de 1994) aprobada por el Pleno del mismo el 21 de noviembre de 2007, y por la que se modifica el artículo 184 añadiéndole un nuevo apartado séptimo (art. único).

En relación a la previsión de la LOTC a favor de que las Comunidades Autónomas puedan participar en la elección por el Senado de los cuatro Magistrados constitucionales que constitucionalmente le corresponde hacer, ésta se integra en una reforma muy amplia y compleja que afecta tanto a la organización, como a las competencias del Tribunal Constitucional, a la par que se introduce y aprueba de manera incidental en ella a la vista del proceso de reformas estatutarias ya aprobadas, y en fase de aprobación, en tal momento (según se ha

legislación estatal, participará en los organismos y procedimientos de toma de decisiones del Estado que afecten a sus competencias y, en particular, en los siguientes ámbitos: [...] Designación de los miembros de las instituciones, organismos y empresas públicas del Estado, en los términos establecidos en la legislación estatal".

21 Ya, STC 247/2007, de 12 de diciembre (FJ núm. 6). Al respecto de esta STC, en tono crítico, cfr. G. FERnÁNDEZ FarReres, ¿Hacia una nueva doctrina constitucional del Estado Autonómico? (Comentario a la STC 247/2007, de 12 de diciembre, sobre el Estatuto de Autonomía de la Comunidad Valenciana), Thomson/Civitas, Madrid, 2008, págs. 21, 22, 49 ss. Asimismo de interés sobre tales reformas estatutarias, vid. nuevamente al mismo autor (y otra vez en tono crítico), "La reforma de la Ley Orgánica del Tribunal Constitucional... cit., págs. 175-177.

22 Además del art. 16.2, 3 y 4 LOTC, conforme art. único, apartado 7. ${ }^{\circ}$, LO 6/2007, en lo que a estas páginas concierne. 
señalado) ${ }^{23}$. Mientras, la reforma del RS se articula exclusivamente a modo de oportuno e inmediato complemento de lo anterior ${ }^{24}$, de acuerdo a la reserva de reglamento parlamentario constitucionalmente prevista (art. 72.1 CE).

En cuanto al vigente artículo 16.1 de la LOTC, a la mera previsión originaria de la propuesta de las cámaras conforme al artículo 159.1 de la Constitución, se le añade un nuevo apartado: «Los Magistrados propuestos por el Senado serán elegidos entre los candidatos presentados por las Asambleas Legislativas de las Comunidades Autónomas en los términos que determine el Reglamento de la Cámara”. Además, se da una nueva redacción al 16.2, de acuerdo al cual «[1]os candidatos propuestos por el Congreso y por el Senado deberán comparecer previamente ante las correspondientes Comisiones en los términos que dispongan los respectivos Reglamentos ${ }^{25}$.

Y respecto al añadido del nuevo párrafo séptimo al artículo 184 del RS, al procedimiento anteriormente descrito ante éste de elección de los Magistrados constitucionales, se establece ahora: «La elección por el Senado de los cuatro Magistrados del Tribunal Constitucional, cuyo nombramiento ha de proponerse al Rey, según lo previsto en el artículo 159 de la Constitución, seguirá el procedimiento previsto en este Capítulo con las siguientes especialidades: / a) El Presidente del Senado comunicará a los Presidentes de las Asambleas Legislativas de las Comunidades Autónomas la apertura del plazo para la presentación de las candidaturas. Cada Asamblea Legislativa podrá, en ese plazo,

23 La adición del segundo apartado al art. 16.1 LOTC no figuraba originariamente en el proyecto del Gobierno, siendo introducido en la fase de Ponencia del Congreso de los Diputados a partir de una enmienda transaccional a varias enmiendas (concretamente, las núm. 17, 44 y 90) que pretendían introducir la participación de las Comunidades Autónomas en la propuesta del Senado de los cuatro Magistrados constitucionales que a éste le corresponde; en general, dichas enmiendas giraban en torno a una propuesta previa por parte de la Comisión General de las Comunidades Autónomas, en tanto que órgano parlamentario abierto a la participación de los Consejos de Gobiernos autonómicos (y así, en la línea de las propuestas de reformas de la LOTC anteriormente comentadas en texto), mas sin llegar a definirse el procedimiento de tales consultas (quedando abierto a remisión normativa). Ello explicaría, sin más, el silencio que al respecto se guarda en la Exposición de Motivos de la LO 6/2007. Por otra parte, respecto al contenido de dichas enmiendas, particular interés nos presenta la núm. 90, a cargo del Grupo Parlamentario Catalán (Convergència i Unió), y conforme a la cual: "Los Magistrados propuestos por el Senado serán designados con participación de las Comunidades Autónomas, a propuesta de la Comisión General de las Autonomías previa consulta a las asambleas legislativas de las Comunidades Autónomas o, de haber alguna disuelta, al órgano colegiado de gobierno, de acuerdo con lo que establezca la Ley propia de cada Comunidad".

24 Vid. Preámbulo de la reforma.

25 También de interés es la nueva redacción que se da al art. 16.3 LOTC, relativo a la renovación del Tribunal Constitucional y a una posible prórroga del mandato del Presidente y Vicepresidente (al respecto de ello, se volverá más adelante con ocasión de la presentación de la STC 49/2008): «La designación para el cargo de Magistrado del Tribunal Constitucional se hará por nueve años, renovándose el Tribunal por terceras partes cada tres. A partir de ese momento se producirá la elección del Presidente y Vicepresidente de acuerdo con lo previsto en el artículo 9. $\mathrm{Si}$ el mandato de tres años para el que fueron designados como Presidente y Vicepresidente no coincidiera con la renovación del Tribunal Constitucional, tal mandato quedará prorrogado para que finalice en el momento en que dicha renovación se produzca y tomen posesión los nuevos Magistrados". 
presentar hasta dos candidatos, resultando aplicable lo dispuesto en los apartados 3 y 4 de este artículo. / b) La Comisión de Nombramientos elevará al Pleno de la Cámara una propuesta con tantos candidatos como puestos a cubrir, que deberán haber comparecido previamente en la Comisión. Si no se hubieran presentado en plazo candidaturas suficientes, la propuesta que se eleve al Pleno podrá incluir otros candidatos".

Mediante ambas reformas, y en estrecha colaboración, se viene finalmente a dar intervención a las Comunidades Autónomas en la elección por el Senado de los cuatro Magistrados constitucionales que a éste le corresponde hacer, en línea de lo apuntado por las recientes reformas autonómicas comentadas; pero ello, y a diferencia ahora de las propuestas de reforma de la LOTC señaladas en el anterior epígrafe, sin previsión de idea alguna de representación y sin intervención de la Comisión General de las Comunidades Autónomas del Senado, dejándolo así nuevamente en manos de la Comisión de Nombramientos, además del Pleno del mismo.

Por último, en cuanto a la constitucionalidad de dichas reformas, quedamos al análisis que de las Sentencias 49/2008 y 101/2008 realizamos en el siguiente epígrafe.

\section{COMENTARIO DE LAS SENTENCIAS DEL TRIBUNAL CONSTITUCIONAL 49/2008 Y 101/2008}

Las Sentencias del Tribunal Constitucional 49/2008, de 9 de abril, y $101 / 2008$, de 24 de julio de 2008, vienen a resolver dos recursos de inconstitucionalidad relativos a la validez de los artículos 16.1 de la LOTC (conforme art. único, apartado $6^{\circ}$, LO 6/2007), y 184.7 del RS (art. único, según reforma del mismo de 21 de noviembre de 2007), respectivamente ${ }^{26}$; y en sendos casos, pronunciándose el Tribunal Constitucional a favor de la constitucionalidad de los respectivos preceptos.

Sin perjuicio del comentario que de ambos pronunciamientos constitucionales seguidamente se ofrece ${ }^{27}$, parece oportuno señalar inicialmente las

26 De un lado, recurso de inconstitucionalidad núm. 6729-2007, de 27 de julio de 2007, e interpuesto por don Ignacio Astarloa Huarte-Mendicoa en su condición de Comisionado de otros sesenta y siete Diputados del Grupo Parlamentario Popular del Congreso, contra el artículo único, apartados 6 y 7, LO 6/2007, dando nueva redacción a los arts. 16.1 y 3 LOTC; y de otro, recurso de inconstitucionalidad núm. 269-2008, de 10 de enero de 2008, e interpuesto por doña María Rosa Vindel López en su condición de Comisionada de otros cincuenta y un senadores del Grupo Parlamentario Popular del Senado, contra el nuevo apartado 7 del art. 184 RS, conforme art. único de la Reforma aprobada el 21 de noviembre de 2007.

27 A tales efectos, comenzaremos con una presentación exhaustiva de las argumentaciones del Tribunal Constitucional, como de los Votos Particulares que acompañan a ambas SSTC, para luego centrarnos en el análisis crítico de los aspectos más interesantes, a nuestro entender, de las mismas. Ciertamente, dicha presentación será extensa (y tal vez excesiva); pero es que la incidencia e importancia de los argumentos constitucionales expuestos, tanto por el Tribunal como por los Magistrados discrepantes, justifica su detalle. 
particulares circunstancias que rodearon la Sentencia 49/2008, dada la abstención de la Presidenta y del Vicepresidente del Tribunal Constitucional, además de la recusación de otros dos Magistrados del mismo a instancia del Gobierno, de manera que el Pleno del Tribunal quedó reducido a su composición mínima de ocho miembros (art. 14 LOTC) ${ }^{28}$.

\section{III.A. ANÁlisis de la Sentencia 49/2008}

Conforme se ha adelantado, el Tribunal Constitucional en su Sentencia 49/2008 resuelve la constitucionalidad del vigente artículo 16.1 de la LOTC; y ello en atención al artículo 159.1 de la Constitución en tanto que, según los recurrentes, "atribuye directa, exclusiva e incondicionadamente la elección de tales Magistrados al Senado", además de "otros preceptos constitucionales relacionados con el sistema de fuentes" (arts. 72 y $165 \mathrm{CE}$ ), con la propia "posición constitucional del Senado" (arts. 67, 69, 70, 71, 72, 73, 74, 75, 76, 77, 78, $79,80,82,87,89,90$ y 91, y en especial 66.1 y $2,67.2$ y 23.1 y 2 CE), y con la misma "estructura territorial del Estado" (básicamente, art. 81.1 CE) y la posición constitucional de los senadores. Mas, y sin perjuicio de la interrelación de "los diversos motivos de inconstitucionalidad aducidos", distinguiendo el Tribunal entre "unos principales (la pretendida vulneración del art. 159.1 CE y, por lo que respecta al sistema de fuentes, de los arts. 72 y $165 \mathrm{CE}$ ) y otros secundarios o [...] consecuenciales o derivados, que dependen en gran medida de la vulneración del art. 159.1 CE» (FJ núm. 1) ${ }^{29}$, y cuyo orden es seguido en la argumentación de aquél.

A tales efectos, y de manera preliminar, el Tribunal Constitucional parte de la peculiaridad que en este recurso supone "dirigirse contra unos preceptos que reforman la Ley Orgánica del Tribunal Constitucional", y situándolo "ante la tesitura de controlar la única Ley a la que, como señala el art. 1.1 LOTC, [están] íntegramente sometidos"; por ello es por lo que, a reglón seguido, se plantee "si resulta posible y, en su caso, con qué alcance, controlar la consti-

28 De una parte, ATC $387 / 2007$, de 16 de octubre, estimando justificadas las abstenciones de la Presidenta y del Vicepresidente del Tribunal Constitucional, ante la posible apariencia de pérdida de imparcialidad a la vista de cómo el art. 16.3 LOTC se refiere al mandato de éstos; de otra, ATC 81/2008, de 12 de marzo, estimando las recusaciones por el Gobierno de la Nación de los Magistrados Roberto García-Calvo y Montiel y Jorge Rodríguez-Zapata Pérez, por concurrir las causas de recusación previstas en los arts. 219.10, 13 y 16 LOPJ; y por último, ATC 443/2007, de 27 de noviembre, inadmitiendo ahora las recusaciones por los recurrentes de los Magistrados Pascual Sala Sánchez, Pablo Pérez Tremps y Manuel Aragón Reyes. En torno a estos dos últimos AATC, vid. L. BACHMAIER WINTER, Imparcialidad judicial y libertad de expresión de Jueces y Magistrados (La recusación de los Magsitrados del Tribunal Constitucional), Thomson/Aranzadi, Pamplona, 2008, págs. 171 y ss.

29 También, sobre la delimitación del objeto del recurso, cfr. FJ núm. 6. Para un conocimiento detallado de los motivos de inconstitucionalidad aducidos por los recurrentes, vid. Antecedente núm. 1.a, b y d; y en cuanto a las alegaciones del Abogado del Estado, en representación del Gobierno, Antecedente núm. 9.b, c y e. 
tucionalidad" de la LOTC (FJ núm. 2) 30. El Tribunal no tiene duda de que el apartado segundo del artículo 16.1 de la LOTC es susceptible de tal control de constitucionalidad (art. 27.2.a LOTC), así como, en su caso, de ser declarado inconstitucional ${ }^{31}$; la libertad de configuración del «legislador orgánico del Tribunal Constitucional" no es absoluta, resultando delimitada por "la propia supremacía constitucional (art. 9.1 CE) " mediante "límites materiales y formales" apreciables tanto en el Título IX de la Constitución, como en el resto de su articulado desde "una interpretación sistemática" de la misma. Otra cosa es, claro está, la función del Tribunal Constitucional de "garantizar ambos aspectos, así como el equilibrio" entre ellos (FJ núm. 3); es de este modo que el examen por el Tribunal de la constitucionalidad de la LOTC obligue a éste a "extremar las consideraciones institucionales y funcionales que siempre acompañan al control del legislador democrático", y que tal juicio sea "exclusivamente de constitucionalidad y no político, de oportunidad o de calidad técnica". No en vano, en tanto que "dicha vinculación se proyecta sobre la propia legitimidad de este órgano", el control de la LOTC "debe limitarse a los supuestos en que existe un conflicto evidente e insalvable entre la misma y el texto constitucional» (FJ núm. 4).

Entrando a continuación een el análisis de las concretas tachas de inconstitucionalidad", mas con carácter general, el Tribunal Constitucional resuelve primero "la pretendida arbitrariedad" del segundo apartado del artículo 16.1 de la LOTC (conforme art. 9.3 CE), ante la carencia de cualquier justificación del mismo "en la exposición de motivos de la Ley Orgánica 6/2007”. Al respecto el Tribunal rechaza tal arbitrariedad, dado que, de un lado, "el silencio de la exposición de motivos carece de trascendencia constitucional y únicamente constituye una imperfección técnico-legislativa, ",2 ${ }^{32}$ y de otro, que dicho precepto tiene «una justificación constitucional clara, aunque pueda ser discutible, 33 (FJ núm. 5).

30 Cierto que en una ocasión la LOTC fue objeto de recurso, pero lo fue en tanto que "preventivamente" por la vía del extinto art. 79 LOTC, y dando lugar a la STC 66/1985, de 23 de mayo; en ella, el Tribunal afirmaría ya la disponibilidad de su contenido para el legislador (FJ núm. 2, nuevamente).

31 Dice más adelante el Tribunal: "Lo contrario supondría no sólo admitir una zona inmune al control de constitucionalidad, sino también hacer dejación de nuestra función en un ámbito tan decisivo para la propia supremacía de la Constitución como la jurisdicción de este Tribunal. La estrecha relación que existe entre la Norma Suprema y la Ley Orgánica del Tribunal Constitucional y que se manifiesta, entre otras cuestiones, en la existencia de una reserva de ley orgánica tan amplia y con vocación de plenitud como la contenida en el art. $165 \mathrm{CE}$, lejos de debilitarla, refuerza la necesidad de controlar que el legislador respete el modelo constitucional de nuestra jurisdicción, puesto que de ello depende en buena medida la efectividad del orden constitucional en todos los ámbitos. Dejar en manos del legislador orgánico la concreción de dicho modelo y renunciar a controlarla no se correspondería, en efecto, con la pretensión del constituyente de crear un órgano de control de constitucional con amplias competencias y de garantizar su eficacia" (FJ núm. 3).

32 «.... que hubiese sido preferible evitar, pero que no es infrecuente en supuestos en que las normas impugnadas son introducidas durante la tramitación parlamentaria" (FJ núm. 5).

33 Según el Tribunal, la motivación del recurso no satisface los requisitos que éste viene exigiendo "a las leyes pretendidamente arbitrarias" (SSTC 239/1992, FJ núm. 5, 47/2005, FJ núm. 7, 
De manera más concreta ahora, y en relación con la supuesta vulneración del artículo 159.1 de la Constitución, no cabe, de un lado (según el Tribunal), "hablar de alteración de la Constitución", sin perjuicio de que toda inconstitucionalidad pueda "contemplarse de algún modo como un intento" ilegítimo de transformar la Constitución, quebrantándola ${ }^{34}$; mientras que, de otro, se ha de interpretar tal precepto no aisladamente, "sino en el contexto de los demás preceptos constitucionales y, en especial, de las normas que integran el título IX CE y, en definitiva, del modelo de Tribunal Constitucional que se deriva de nuestra Norma Suprema" (FJ núm. 7). En este sentido, "la Constitución española contiene una regulación detallada de la elección de los miembros del Tribunal Constitucional", sin perjuicio de que "no cierr[e] las puertas de modo absoluto a que otras normas puedan desarrollar una regulación constitucional que, entre otras cosas, guarda silencio sobre el procedimiento a seguir en dicha elección" (FJ núm. 7.a) ${ }^{35}$; y así, y aun cuando atribuye a las Cortes Generales la elección de ocho de los doce Magistrados constitucionales (lo que resulta congruente con la especial posición de la misma en el diseño que de la forma de gobierno parlamentaria realiza la CE) en una situación de paridad de las dos Cámaras que la componen "en cuanto al número de Magistrados a elegir y la mayoría necesaria para ello", no cabe sin embargo una total equiparación entre ambas en relación al concreto modo de ejercer tal facultad, que puede estar influido por las propias características constitucionales de cada Cámara" (FJ núm. 7.b) ${ }^{36}$. A estos efectos, para el Tribunal resulta claro que el vigente artículo 16.1 de la LOTC no desapodera al Senado en su elec-

13/2007, FJ núm. 4, y 45/2007, FJ núm. 4): que la invocación de la arbitrariedad se razone «en detalle, ofreciendo una justificación en principio convincente para destruir la presunción de constitucionalidad de la ley impugnada"; y que dicha arbitrariedad sea el resultado de una discriminación normativa o de la "carencia absoluta de explicación racional de la medida adoptada, pero en ningún caso de una discrepancia política respecto de su contenido". Es más, y al contrario, la reforma del art. 16.1 LOTC sí tiene una "explicación racional", ya que pretende "canalizar la participación de las Comunidades Autónomas en la elección de determinados Magistrados del Tribunal Constitucional", al margen de que ello no sea compartido por los recurrentes (FJ núm. 5).

34 No en vano, la histórica Sentencia "Merbury versus Madison", del Tribunal Supremo norteamericano (1803), planteaba ya la íntima conexión existente entre inconstitucionalidad, supremacía constitucional y rigidez en la reforma constitucional.

35 Sigue diciendo el Tribunal: "Aunque se da la paradoja que el art. 159.1 CE es una norma más completa que el original art. 16.1 LOTC, no existe impedimento constitucional para que la regulación constitucional sea desarrollada y concretada siguiendo los requisitos formales y materiales que se derivan del texto constitucional” (FJ núm. 7.a, in fine).

36 A ello añade el Tribunal: "A su vez, tampoco puede desconocerse que la facultad de elegir a un determinado número de Magistrados también tiene una dimensión de deber constitucional y de deber institucional que se relaciona con la lealtad constitucional —que, como señalamos en la STC 209/1990, de 20 de noviembre, FJ 4, obliga a todos-, y que en el ámbito que nos ocupa está en el origen de regulaciones como la prevista en el art. 17.1 LOTC» (FJ núm. 7.b, in fine); "Finalmente, también cabe señalar que la elección de los miembros del Tribunal Constitucional no puede desvincularse de los requisitos de elegibilidad, capacidad e independencia que se derivan de los apartados segundo, cuarto y quinto del art. 159 CE, así como del carácter parcial, pero por bloques, de la renovación periódica de este órgano (art. 159.3 CE)" (FJ núm. 7.c). 
ción de cuatro Magistrados constitucionales (FJ núm. 8), pues, y aún materialmente: de un lado, a tenor de la "amplitud de la remisión que se hace al Reglamento parlamentario", el específico "régimen jurídico de la presentación de candidaturas por parte de los Parlamentos autonómicos y de la elección de los Magistrados entre dichos candidatos, lejos de concretarse, se remiten íntegramente" al RS, lo que a su vez abre "las puertas a múltiples desarrollos" ${ }^{37}$; y de otro, y en el marco asimismo de dicha remisión al RS, no se impide que finalmente sea éste quien efectivamente haga la referida elección al no excluir "cualquier posible margen de maniobra por parte del Senado". Es más, los términos en que está redactada la remisión al RS no cierra "las puertas a que el propio Senado pueda velar por el ejercicio constitucionalmente correcto de su función si, por ejemplo, el número de candidatos presentados es insuficiente, si considera que los candidatos propuestos no cumplen los requisitos exigidos constitucionalmente, o si la elección de algunos de los Magistrados se frustra

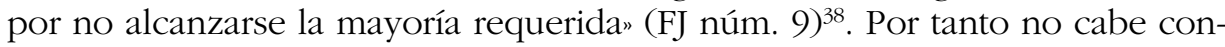
siderarse, siempre según el Tribunal Constitucional, "que el precepto impugnado desapodere al Senado del ejercicio material de una de sus funciones constitucionales", ni que "se produzca necesariamente una renuncia, traslado o sustitución del Senado por parte de los Parlamentos autonómicos, o la sustracción de una facultad constitucional mínima, puesto que ello implicaría desconocer que la norma impugnada admite una lectura que impide considerar que el papel del Senado sea meramente formal" (FJ núm. 9, in fine). Y tam-

37 Continúa el Tribunal: "Por lo que a la presentación de candidaturas a Magistrado se refiere, lo único que se prevé es que la misma corresponde a los Parlamentos autonómicos. No se dice nada, en cambio, ni del procedimiento a seguir, ni del número de candidatos que cabe presentar, ni de si deben cumplir algún requisito que los vincule a la respectiva Comunidad Autónoma, ni de si es posible presentar candidaturas sucesivas a iniciativa del Senado o del propio Parlamento autonómico. Aunque los términos que se emplean en el precepto permiten configurarlo como un deber y no sólo como una facultad, son el Reglamento del Senado y los Reglamentos de cada Parlamento autonómico los que deben concretar el régimen jurídico de dicho deber. Lógicamente, dicha concreción debe tener en cuenta no sólo el respectivo ámbito de actuación de los diversos Reglamentos parlamentarios, sino también que los candidatos a Magistrado deben cumplir los requisitos exigidos constitucionalmente para poder desempeñar su función y que la elección de los Magistrados por parte del Senado no puede ser obstaculizada por la actuación de los Parlamentos autonómicos. En todo caso, el régimen jurídico aplicable a las propuestas de candidatos a Magistrado por parte de las Asambleas autonómicas no se agota en el art. 16.1 LOTC" (FJ núm. 9).

38 Sigue el Tribunal: "En definitiva, tal y como está redactada la norma impugnada no puede dejar totalmente en manos de los Parlamentos autonómicos la libre determinación de los candidatos elegibles por el Senado, sino que remite a su Reglamento y, por lo tanto, a la propia voluntad de la Cámara, la concreción del grado de participación de los Parlamentos autonómicos en dicha facultad, así como el margen de intervención del Senado en el proceso de elección de los Magistrados del Tribunal Constitucional. Como es lógico, tal remisión no implica que el Reglamento del Senado no esté sometido a límites constitucionales que permitan a la Cámara ejercer adecuadamente su función constitucional, ni que este Tribunal no pueda controlar que el concreto desarrollo de la participación autonómica en el proceso de elección de sus Magistrados respeta tales límites. Pero la posibilidad de que éstos se sobrepasen no puede llevarnos a considerar que, tal y como está redactado, el precepto impugnado sea inconstitucional" (FJ núm. 9). 
poco cabe, para concluir esta cuestión, que el artículo 159.1 de la Constitución conlleve una facultad al Senado "absoluta e ilimitada", ya que, aunque la regulación del artículo 159.1 es extensa, "requiere necesariamente desarrollo normativo", lo cual supone, a su vez, que pueda "verse limitada tanto material como procedimentalmente", a fin de velar adecuadamente "por los requisitos de elegibilidad, capacidad e independencia que la Constitución también exige a los candidatos" a Magistrado constitucional (FJ núm. 10).

Ciertamente, el vigente artículo 16.1 de la LOTC presenta, no obstante (para el Tribunal), "un elemento cualitativo diferente, cual es el de introducir por vez primera la participación de órganos ajenos al Senado en la elección" de los Magistrados constitucionales, siendo dicha participación y, concretamente, la intensidad de la misma, donde se centraría y "anudan los restantes problemas de constitucionalidad". A estos efectos, y dejando para más adelante el problema de fuentes del Derecho, el Tribunal Constitucional pasa a analizar: si la participación de los Parlamentos autonómicos en la elección de Magistrados por parte del Senado está constitucionalmente prohibida; si ello no es así, si dicha participación tiene un fundamento constitucionalmente legítimo que la justifique; y "si su intensidad resulta compatible con el modelo de jurisdicción constitucional que se deriva de nuestra Norma Suprema" (FJ núm. 11). En cuanto a lo primero, la Constitución no impide expresamente "que las Asambleas de las Comunidades Autónomas puedan intervenir en la elección de Magistrados del Tribunal Constitucional presentando candidatos al Senado" (FJ núm. 12) ${ }^{39}$. Y de otro lado, el carácter de Cámara de representación territorial del Senado puede expresarse y desarrollarse no sólo en la organización y funciones del mismo, sino en «el ejercicio de todas sus facultades y, concretamente, de la elección de los miembros del Tribunal Constitucional que le corresponden"; es más, tal decisión constitucional denota una voluntad «inequívoca de integrar la estructura territorial del Estado en la composición del Tribunal Constitucional, órgano que, también por decisión constitucional, tiene la facultad de conocer de los conflictos de competencia entre el Estado y las Comunidades Autónomas" (FJ núm. 13) ${ }^{40}$. Finalmente, tampoco la participación de las Comunidades que conlleva el artículo 16.1 de la LOTC «puede ser calificada de inconstitucional por su intensidad y resultado", puesto que ésta "se limita, en efecto, a la fase de presentación de candidatos y no implica

39 Y es que no estando ello previsto, "la competencia constitucional de la Cámara Alta de elegir a cuatro de los doce Magistrados no puede interpretarse como una prohibición constitucional implícita a que los Parlamentos autonómicos intervengan en dicha elección mediante la presentación de candidatos" (FJ núm. 12).

40 "De la interpretación conjunta de los arts. 69 y 159.1 CE puede derivarse, en efecto, un principio de participación autonómica en la composición del Tribunal susceptible de ser desarrollado de diversos modos. La regulación impugnada constituye uno de ellos, por cuanto, como se ha visto, articula dicha participación a través de la propuesta de candidatos por parte de los Parlamentos autonómicos. [...] Pero en todo caso, lo que interesa destacar a los efectos de nuestro enjuiciamiento es que la participación de las Comunidades Autónomas en dicha elección constituye una finalidad que puede perseguirse legítimamente en nuestro sistema constitucional" (FJ núm. 13). 
que el Senado deje de ser el titular de dicha facultad"; la amplitud de la remisión reglamentaria referida "abre las puertas a múltiples concreciones y diversas intensidades de participación que, tal y como está redactado el precepto, no impiden que el Senado pueda hacer frente a los problemas que pueden derivarse de la inactividad de los Parlamentos autonómicos o de la frustración de sus propuestas", y así que el RS "pueda, entre otras fórmulas, prever, incluso, mecanismos que hagan posible que sea la propia Cámara la que proponga candidatos a Magistrados del Tribunal Constitucional en el supuesto excepcional de que el sistema de elección de dichos Magistrados previsto con carácter general no culmine con esta elección, garantizando así que la Cámara Alta cumpla con su obligación constitucional" (FJ núm. 14).

Respecto a los otros motivos de inconstitucionalidad (y comenzando por los relacionados con el sistema de fuentes), por lo que concierne a la reserva de Reglamento parlamentario (art. 72.1 CE), es evidente para el Tribunal Constitucional que el vigente artículo 16.1 de la LOTC «afecta al modo de ejercicio de una facultad del Senado", pero sin llegar a vulnerar tal reserva por cuanto que: de un lado, "excede claramente la vida interna del Senado, al dar entrada a los Parlamentos autonómicos en el ejercicio de dicha facultad ${ }^{41} ; \mathrm{y}$ de otro, la amplia remisión que plantea la LOTC al RS garantiza que sea el Senado el que, "en ejercicio de su autonomía, pueda concretar el régimen jurídico de dicha participación, así como el procedimiento de elección definitiva de los Magistrados" (FJ núm. 15). Y en cuanto al hipotético exceso que supone el apartado segundo del referido artículo 16.1 de la LOTC respecto que a la reserva misma de LOTC que contiene el artículo 165 de la Constitución, los términos en los que se formula tal reserva "le otorgan una vocación de complitud", la cual, aunque "no impide que otras leyes orgánicas incidan en el alcance de la jurisdicción constitucional", la LOTC "constituye el cauce constitucionalmente idóneo para introducir una participación autonómica en la elección" de los Magistrados constitucionales, la cual "es legítima desde un punto de vista material»; más aún, "en la medida en que dicha participación excede la esfera interna del Senado y precisa el concurso de los Parlamentos autonómicos, es dicha Ley, que no está vinculada positiva sino negativamente a la Constitución, la única fuente del Derecho - excepto la propia Constitución- que puede introducirla" (FJ núm. 16) ${ }^{42}$.

41 "En la medida, además, en que dicha participación va más allá de un mero trámite de audiencia o de consulta, otorgando a los Parlamentos autonómicos un papel más activo en la fase de presentación de candidaturas, no sería posible que el Reglamento del Senado introdujese unilateralmente una participación de este tipo, que, como se ha señalado anteriormente, obliga a las Asambleas autonómicas a presentar candidatos a Magistrado" (FJ núm. 15).

42 "No cabe aquí trasladar a la Ley Orgánica del Tribunal Constitucional la doctrina sobre el carácter estricto de las reservas de leyes orgánicas, pues se trata de un supuesto enteramente diferente. Aquellas reservas pueden ser interpretadas estricta o incluso restrictivamente porque el ordenamiento tiene a su disposición otro instrumento (la ley ordinaria) para regular aquello que se le veda a la ley orgánica. No ocurre así con la reserva prevista en el art. 165 CE, ya que únicamente la Ley Orgánica del Tribunal Constitucional y no cualquier otra ley puede desarrollar la institución del Tribunal Constitucional en todos los ámbitos en que quepa tal desarrollo, bien por 
Ya finalmente, en relación con la posición constitucional del Senado, descartado que el artículo 16.1 de la LOTC suponga "un desapoderamiento del Senado", resulta evidente que no se ha vulnerado tampoco "la posición constitucional de esta Cámara "43; e igualmente acontece respecto a la organización territorial del poder, y al estatuto constitucional de los senadores (FJ núm. $17)^{44}$.

De otra parte, el parecer de la mayoría del Tribunal Constitucional resultó contestado por tres Votos Particulares, a favor de la estimación del recurso de inconstitucionalidad; los de los Magistrados don Vicente Martín de Hijas, don Javier Delgado Barrio, y don Ramón Rodríguez Arribas. En cuanto al primero de ellos, don Vicente Martín de Hijas considera "clara" la inconstitucionalidad de la adición del segundo párrafo del artículo 16.1 de la LOTC, dado que, y en el plano formal del sistema de las fuentes del Derecho, es contrario a los artículos 72.1 y 165 de la Constitución, mientras en un plano material, contraviene lo dispuesto en el artículo 159.1 de la misma por afectar negativamente la posición institucional del Senado ${ }^{45}$; y es que, según éste, el Sena-

requerirlo la Constitución, bien porque no esté constitucionalmente impedido. Tratándose, además, de un aspecto que no afecta a las competencias del Tribunal, es sólo, pues, la Ley Orgánica del Tribunal Constitucional, y no otras leyes orgánicas, la que puede desarrollar la previsión constitucional de elección de los Magistrados por parte de la Cámara de representación territorial, previendo una participación de las Asambleas Legislativas de las Comunidades Autónomas" (FJ núm. 16, in fine).

43 Argumenta el Tribunal Constitucional: «En la medida, en efecto, en que la regulación recurrida se limita a hacer posible la participación de las Comunidades Autónomas en el ejercicio de una función del Senado, ni se vulnera el principio de representación nacional que se deriva de dicho precepto ni se produce una discriminación respeto del Congreso de los Diputados, Cámara que carece del carácter de representación territorial que define la posición constitucional del Senado (art. $69 \mathrm{CE}$ ) y que, como se ha visto, legitima constitucionalmente la participación autonómica en la elección de los Magistrados que le corresponde" (FJ núm. 17).

44 "Así, puesto que no se ha alterado el sistema de distribución de competencias entre el Estado y las Comunidades Autónomas, sino que simplemente se hace posible la participación autonómica en una facultad del Senado no puede hablarse de una sustitución del Senado por parte de los Parlamentos autonómicos, ni de una vulneración del art. 81.1 CE por utilizarse la Ley Orgánica del Tribunal Constitucional para otorgar competencias a las Comunidades Autónomas, ni de una ampliación de las competencias de sus Asambleas Legislativas previstas constitucionalmente [arts. 147.2 c) y $152.1 \mathrm{CE}$. Y tampoco se ha producido una vulneración del estatuto constitucional de los Senadores protegido por los arts. 23.2 y $67.2 \mathrm{CE}$. Por un lado, porque dicho estatuto es de configuración legal y, por lo tanto, admite que se regule y limite el ejercicio de sus funciones parlamentarias. Y por otro, porque la regulación impugnada no puede considerarse que vulnere la prohibición constitucional de mandato imperativo al atribuir a los Senadores la facultad de elegir a los Magistrados del Tribunal Constitucional al final de un procedimiento en el que se ha previsto la participación autonómica. En la medida, finalmente, en que no se ha infringido el art. 23.2 CE tampoco puede considerarse vulnerado el art. 23.1 CE que, como reconocen los propios recurrentes, sólo se vería afectado por extensión" (FJ núm. 17, in fine).

45 «En mi criterio, cuando la Constitución en el art. 159 regula la composición del Tribunal Constitucional, deja perfectamente agotados los extremos esenciales del régimen jurídico de la misma y del alcance de las facultades que atribuye a los órganos constitucionales llamados a proponer al Rey los nombramientos de Magistrados en la parte que a cada uno de dichos órganos constitucionales corresponde. Y en el ámbito definido y cerrado por la Constitución no cabe disponibilidad alguna de la materia por el legislador. Si el legislador se introduce en ese ámbito, a 
do no puede elegir Magistrados constitucionales que no hayan sido previamente propuestos por las Asambleas Legislativas de las Comunidades Autónomas, "con lo que se atribuye a esas Asambleas una intervención condicionante en el proceso de selección de los Magistrados del Tribunal Constitucional en la parte que corresponde al Senado, que ni está prevista en lugar alguno de la Constitución, ni tiene encaje posible en la definición constitucional de las funciones de las Comunidades Autónomas reguladas en el título VIII CE». A estos efectos, además, el Magistrado alega no estar de acuerdo con la posibilidad que abre la mayoría del Tribunal en relación a que el Senado quepa apartarse de tal propuesta (en FFJJ núms. 9 y 14), de manera que el Tribunal salva "la constitucionalidad del precepto impugnado, a base de difuminar el sentido claro de lo que dice, convirtiéndolo en la interpretación de la Sentencia en un precepto distinto, irreconocible en su prístino sentido"; y de otro lado, el que la Constitución no prohíba expresamente la intervención de las Comunidades en la elección de los Magistrados constitucionales (FJ núm. 12), así como la configuración constitucional del Senado como Cámara de representación territorial (FJ 13), no son razón para que mediante la reforma de la LOTC se pueda "dar participación en la dinámica de su ejercicio a órganos estatutarios de los territorios representados en la Cámara".

En una línea similar, el Magistrado don Javier Delgado Barrio sostiene la inconstitucionalidad del artículo 16.1, párrafo segundo, de la LOTC en atención a la absoluta libertad que el artículo 159.1 de la Constitución confiere al Senado en relación a la elección de los cuatro Magistrados que le corresponde ${ }^{46}$, además del "carácter exhaustivo" de dicho precepto constitucional respecto a su regulación por la LOTC. Asimismo, el Magistrado don Ramón Rodríguez Arribas insiste en la libertad del Senado en tal elección, mientras que "la norma legal cuestionada introduce una restricción en la capacidad de elección del Senado, que ya no puede elegir entre cualesquiera juristas que reúnan las condiciones constitucionalmente establecidas, sino sólo entre los que, además, hayan sido previamente presentados por dichas Asambleas Legislativas, con lo que la inconstitucionalidad resulta patente e insalvable»; y ello, sin que resulte solventado desde la interpretación que la mayoría del Tribunal atribuye al artículo 16.1 de la LOTC en relación a la posibilidad de que el Senado elija finalmente entre juristas no propuestos previamente por las Asambleas autonómicas (FFJ 9 y 14), dado que interpretación "contra legem, al pretender hacer decir a la reforma legal lo que, evidentemente, no dice ${ }^{47}$.

menos que se limite a la simple reproducción de lo dispuesto en la Constitución, está invadiendo un área que le está vedada, y sólo por ello (o nada menos que por ello) la Ley en la que se produzca esa intromisión debe calificarse de inconstitucional.

46 «[...] se ha desapoderado al Senado para la primera operación — selección de juristas-, de trascendental importancia, reduciéndolo a una especie de elector de segundo grado, en la medida en que opera sobre elementos subjetivos que le vienen dados".

47 "Precisamente ese es el eje de la cuestión, porque si bien ninguna inconstitucionalidad plantea la intervención de las Comunidades Autónomas en la selección de los candidatos que el 


\section{III.B. AnÁlisis De la Sentencia 101/2008}

Respecto a la Sentencia 101/2008, ahora, el Tribunal Constitucional resuelve la constitucionalidad del artículo 184.7 del RS en relación al desapoderamiento que del Senado denuncian los recurrentes con ocasión de la elección de los cuatro Magistrados que constitucionalmente le corresponde, pues dicho precepto impide, según aquéllos, propuestas propias distintas a las de las Asambleas Legislativas de las Comunidades Autónomas (FJ núm. 1) ${ }^{48}$. A tales efectos, el Tribunal comienza recordando la anterior Sentencia 49/2008, lo que le lleva, "en coherencia con la doctrina establecida en la misma", a rechazar diversas tachas de inconstitucionalidad ya resueltas en ésta (FJ núm. 3), pasando inmediatamente a examinar las alegaciones específicamente dirigidas contra el nuevo apartado 7 del artículo 184 del RS, el cual concreta el régimen jurídico de la participación de las Asambleas autonómicas en el procedimiento de elección de los Magistrados constitucionales por el Senado: es decir, y conforme a la referida Sentencia 49/2008, "la segunda fase o momento en la elección de los miembros del Tribunal Constitucional" o "elección definitiva" de éstos por dicha Cámara. En este sentido el Tribunal rechaza seguidamente el que el artículo 184.7 del RS impida al Senado "descartar candidatos presentados por los Parlamentos autonómicos que no reúnan los requisitos constitucional y legalmente establecidos para ser nombrados" Magistrados constitucionales, pues éste deja "claramente" en manos del Senado "la facultad de controlar" que tales candidatos cumplen los requisitos constitucionalmente exigidos; y ello en atención a "la apertura del plazo para la presentación de candidaturas por los Parlamentos autonómicos", la elaboración "por la Comisión de Nombramientos del Senado de una propuesta que incluya tantos candidatos como puestos a cubrir a fin de que la misma sea sometida a la aprobación del Pleno", y "la facultad conferida a dicha Comisión a fin de que pueda proponer candidatos distintos de los propuestos en sede autonómica, en el caso de que no se hubieran presentado en plazo candidaturas suficientes" (FJ núm. 4).

En cuanto a lo primero, el artículo 184.7 del RS establece la obligación del Presidente del Senado de comunicar «a los Presidentes de las Asambleas Legislativas de las Comunidades Autónomas la apertura del plazo para la presentación de candidaturas", con lo que "la presentación de candidatos a Magistrados se formula como una posibilidad o facultad de las Cámaras autonómicas"; ello responde, conforme al artículo 16.1 de la LOTC, a la potencialidad

Senado pueda proponer al Rey, lo que sí vulnera la Constitución es que el Senado solo pueda hacer esa propuesta eligiendo entre los que le vienen señalados desde fuera de la institución, cuando es al Senado al que el art. 159 CE ha confiado, en exclusiva, la función de propuesta; mutación - la de haber de limitarse la Cámara Alta de las Cortes Generales a elegir entre los candidatos previamente presentados por las Asambleas Legislativas de las Comunidades Autónomas- que solo con la reforma de la Constitución misma sería posible".

48 Los argumentos de los recurrentes se encuentran en el Antecedente núm. 2; y las alegaciones del Senado en el núm. 4, y las del Gobierno en el núm. 5. 
de que los Parlamentos autonómicos intervengan en la elección de los Magistrados constitucionales, configurándose como "la primera fase o momento de dicha elección" (conforme STC 49/2008, FJ núm. 9, in fine). Mas tal facultad, añade el Tribunal Constitucional, "no puede obviar que el Senado está compelido a cumplir, en todo caso, con la función y deber constitucional que tiene encomendado en exclusiva, de conformidad con el art. 159.1 CE, en relación con el art. 66.2 CE». Así la Constitución exige un perfil específico para tales candidatos, de acuerdo al cual éstos deben "pertenecer a determinadas categorías profesionales" y haber ejercido profesionalmente "durante un determinado período de tiempo"; y, especialmente, han de ser juristas "de reconocida competencia en la función o profesión respectiva" (art. 159.2 CE), lo que supone, finalmente, "un juicio de valor, referido a la competencia profesional de los candidatos, cuya apreciación corresponde, en primera instancia, a los habilitados por la Ley Orgánica del Tribunal Constitucional y el Reglamento del Senado para proponer candidatos y en definitiva, al legitimado para formular la propuesta de nombramiento al Rey y que no ha de ser apreciada en abstracto sino, precisamente, en atención al desempeño profesional del concreto candidato presentado" (FJ núm. 5). Por tanto, resulta aplicable a la presentación de candidatos por los Parlamentos autonómicos el artículo 184.3 y 4 del RS, de manera que: de un lado, sobre dichos Parlamentos pesa "la carga de acreditar que los candidatos presentados cumplen los requisitos exigidos por la Constitución y las leyes para desempeñar el cargo", lo que lleva aparejado, también, la obligación "de exponer los méritos profesionales y demás circunstancias que indiquen, en opinión del proponente, la idoneidad de los candidatos presentados para el pueston; a la par que, de otro (y significativamente), quepa admitir ula posibilidad de que la Mesa de la Cámara, previa, en su caso, solicitud a la Comisión de Nombramientos de su criterio al respecto, pueda decidir sobre la inadmisión de las candidaturas presentadas si aprecia, en alguno de los candidatos propuestos, el incumplimiento de los requisitos constitucional y legalmente exigibles, inadmisión que determinaría, llegado el caso, la presentación, por los Parlamentos autonómicos, de nuevos candidatos, en el plazo al efecto establecido por la Mesa del Senado, en aplicación de la previsión del art. 184.4 RS, al que expresamente remite" el nuevo 18.4.7.a (FJ núm. 5).

Ahora bien, el cumplimiento de los requisitos señalados por los concretos candidatos propuestos por los Parlamentos autonómico, en esta primera fase, no garantiza su "elección en la segunda y definitiva fase, correspondiente en exclusiva al Senado, pues esto último dependerá, evidentemente, de la decisión que al respecto adopte el Pleno de la Cámara Alta mediante el voto secreto e individual de sus miembros" (FJ núm. 5, in fine). Así, y en cuanto a la segunda cuestión (la propuesta que la Comisión de Nombramientos ha de realizar al Pleno de la Cámara), y más allá de la competencia inicial de la Mesa del Senado de controlar (en el momento de la admisión a trámite de la candidatura) el "cumplimiento de los requisitos exigidos para desempeñar el cargo" (conforme se ha señalado más arriba), corresponde a la Comisión de 
Nombramientos del Senado examinar especialmente la idoneidad de los candidatos propuestos a fin de elevar al Pleno la correspondiente propuesta"; y a estos efectos, se prevé ante la misma "la necesaria comparecencia de los candidatos, solicitándoles aclaraciones sobre cualquier extremo relacionado con su trayectoria profesional o sus méritos personales (art. 185.4 RS)", y "estableciéndose que la no comparecencia elimina la posibilidad de someter la propuesta al Pleno" (FJ núm. 6) ${ }^{49}$. Consecuentemente, "se colige con facilidad que nada pueda oponerse al hecho de que, de acuerdo con el precepto impugnado, la Comisión de Nombramientos del Senado, una vez formado su criterio acerca de la concurrencia en los candidatos de los requisitos necesarios para su designación como Magistrados, eleve, en su caso, al Pleno de la Cámara una propuesta con tantos candidatos como puestos a cubrir" (FJ núm. 6). Pero ello es sólo "una previsión procedimental interna en orden al cumplimiento de la función asignada por el art. 159.1 CE", de manera que "no compele al Pleno a aceptar la propuesta formulada, ya que este último órgano expresa, mediante la requerida votación, su propio juicio sobre los candidatos propuestos por la Comisión de Nombramientos" (FJ núm. 6, in fine).

Y en cuanto a la tercera cuestión, la facultad de la Comisión de Nombramientos para incluir candidatos distintos de los inicialmente propuestos, ésta «responde a la necesidad de establecer una cláusula de cierre aplicable para el caso de que el sistema ordinario de elección, derivado de lo dispuesto en el art. 16.1 LOTC, no permitiera al Senado ejercer, conforme al art. $159.1 \mathrm{CE}$, su facultad de designación" (FJ núm. 7). Al respecto, parece claro (según, siempre, el Tribunal Constitucional) que, a fin de la evaluación de la cualificación constitucionalmente exigida para el desempeño del cargo de Magistrado constitucional, el Senado haya de establecer su propia previsión procedimental para "optar, de entre los diversos candidatos que responden al perfil determinado en las normas aplicables, por aquéllos que sean avalados por la votación cualificada en el seno de la Cámaran. Y que, consecuentemente, la propuesta de candidatos que el Senado eleve a nombramiento real dependa, finalmente: primero, «del cumplimiento por los mismos de los requisitos exigidos" en el artículo 159 de la Constitución (lo que deberá estar ya justificado por los Parlamentos proponentes, para ser luego "oportunamente valorado por los órganos de la Cámara Alta, con carácter previo a la decisión final de ésta última"); segundo, "resultará precisa la inclusión del candidato o candidatos en la propuesta que la Comisión de Nombramientos formule al efecto"; y tercero, «la obtención de la mayoría constitucionalmente requerida en la votación plenaria” (FJ núm. 7) ${ }^{50}$.

49 Tal comparecencia tiene por finalidad, según el Tribunal, "valorar las cualidades de los candidatos para que la Comisión de Nombramientos pueda formarse el oportuno criterio a fin de elevar la propuesta que ha de realizar al Pleno en relación a un nombramiento de tan alta significación" (FJ núm. 6).

50 «[...] votación en la cual, en coherencia con la prohibición constitucional de mandato imperativo derivada del art. $23 \mathrm{CE}$, se expresa la libre facultad de la que han de gozar los Senadores para elegir a los Magistrados del Tribunal Constitucional, a fin de poner así término a un procedimiento en cuya fase inicial se ha previsto la participación autonómica" (FJ núm. 7, in fine). 
A tales efectos, el Tribunal Constitucional pasa a recordar cómo en su anterior Sentencia 49/2008 se negaba ya la posibilidad de que los Parlamentos autonómicos pudieran con su actuación obstaculizar la elección por el Senado de los magistrados constitucionales (STC 49/2008, FJ núm. 9). Así, y para el caso, "improbable pero no imposible, de que hubieran sido presentados menos candidatos que puestos a cubrir", "la dicción literal del precepto impugnado" permite al Senado reaccionar mediante una propuesta propia de candidatos, conforme al artículo 184.7.b, in fine, del RS; y para el supuesto en que éste apreciara ahora que alguno de los candidatos propuestos por los Parlamentos autonómicos no reúna los requisitos exigibles, igualmente cabría interpretar aplicable el artículo 184.7.b del RS (siempre según el Tribunal), de manera que el Senado nuevamente se encontraría habilitado para "tomar en consideración otras candidaturas distintas surgidas en su propio seno, a fin de evitar la paralización del proceso de designación". Con ello, el Constitucional entra en el alcance de la "libertad de rechazo" del Senado de las candidaturas presentadas por los Parlamentos autonómicos (FJ núm. 8) ${ }^{51}$.

Al respecto, y primeramente, el Tribunal Constitucional se reitera en su doctrina de apurar todas las posibilidades de interpretar los preceptos de conformidad con la Constitución y declarar tan sólo la derogación de aquellos cuya incompatibilidad con ella resulte indudable por ser imposible llevar a cabo dicha interpretación"; y de esta forma que, al no estar "ante un supuesto en el que exista un conflicto evidente e insalvable entre el precepto reglamentario impugnado y las normas o principios constitucionales que integran su parámetro de control" (el art. 159.2 CE), quepa atender al "principio de conservación de la norma" (FJ núm. 9). Bajo este marco, estima el Tribunal que el Senado «es plenamente libre en relación con el juicio de idoneidad que le merezcan las distintas candidaturas ante ella presentadas " 52 ; y ello no "sólo en cuanto al cumplimiento de los requisitos de naturaleza puramente objetiva", como la condición de jurista y el tiempo de ejercicio, sino de otros de carácter ya más subjetivos, como el reconocido prestigio, hasta llegar a un criterio de "estricta discrecionalidad política" en virtud del cual la

51 «Esto es, hay que decidir si la Cámara, en realidad, es efectivamente libre para no aceptar a los candidatos propuestos por los Parlamentos autonómicos, pues es obvio que si la Cámara sólo tuviera una capacidad de rechazo, reactiva, frente a las propuestas autonómicas, su libertad de elección sólo habría quedado asegurada con el sacrificio de su obligación de designar cuatro Magistrados" (FJ núm. 8, in fine).

52 "En principio, debemos partir de que la valoración respecto a si las candidaturas presentadas resultan ser suficientes corresponde apreciarla en exclusiva al Senado en el curso del procedimiento encaminado a la designación de Magistrados del Tribunal Constitucional que la propia Cámara ha establecido. De acuerdo con dicho procedimiento, la referida cuestión, relacionada con la necesaria apreciación por parte de los órganos del Senado (Mesa, Comisión de Nombramientos y Pleno, sucesivamente) del cumplimiento por los candidatos presentados de los requisitos para ser nombrado Magistrado del Tribunal Constitucional así como de su idoneidad para el cargo, puede suscitarse en diversos momentos durante el proceso de designación e igualmente solventada de modos también diversos, a algunos de los cuales ya nos hemos referido en la presente Sentencia" (FJ núm. 9). 
Cámara "termina decidiéndose por cuatro concretos candidatos". Es por ello por lo que el nuevo procedimiento de selección de candidatos a Magistrados constitucionales por el Senado "no puede abocar indefectiblemente a aceptar en todo caso a los propuestos por los Parlamentos autonómicos». Esto, a su vez, guardaría relación con la situación excepcional en la que los candidatos inicialmente presentados por las Asambleas autonómicas no recibiesen el apoyo necesario en la Comisión de Nombramientos ("a fin de figurar en la propuesta que a la misma cumple formular"); o si, y alcanzado inicialmente tal apoyo, finalmente, y sin embargo, "todos o algunos de los propuestos por dicha Comisión no alcanzaren en el Pleno de la Cámara la mayoría mínima de tres quintos que la Constitución establece para su designación". Ambas situaciones que, "por el riesgo de conducir a la paralización del proceso de designación", han de ser evitadas en razón de la relevancia constitucional de tal designación por el Senado (según se ha adelantado). Así, y al amparo del referido "principio de conservación de la norma", y conforme a la anterior Sentencia 49/2008 (en especial, ahora, FJ núm. 14), no cabe una interpretación literal de "la referencia del precepto impugnado a la falta de candidatos "suficientes", en un sentido "meramente numérico", de manera que ella cubra tanto la presentación por los Parlamentos autonómicos "de candidatos bastantes en relación con los puestos a cubrir", como "también en otro cualitativo o de mérito, de forma que, en este segundo sentido, solamente serán consideradas suficientes las candidaturas de aquellas personas, sobre las que pueda recaer el apoyo de la Cámara expuesto en la exigencia de que obtengan el voto favorable de, al menos, tres quintos de los Senadores" (FJ núm. 9) $)^{53}$.

Con todo, el Tribunal Constitucional es consciente de la dificulta que supone la anterior interpretación cuando, a continuación, profundiza en la dicción literal del "término "suficiente", entendiendo admisible (conforme a la Real Academia Española) la acepción de "apto o idóneo"; y con ello, que la insuficiencia a valorar por la Comisión de Nombramiento no se limite a constatar la ausencia de candidatos propuestos por los Parlamentos autonómicos, sino también en relación a que los efectivamente propuestos

53 Sigue diciendo el Tribunal: "En efecto, ha de repararse en que la referencia a la suficiencia de candidaturas [art. 184.7 b) RS] se hace en un momento del procedimiento posterior a la admisión de las presentadas por las Asambleas Legislativas (art. 184.4 RS) y, concretamente, tras la comparecencia ante la Comisión de Nombramientos de los candidatos admitidos. Es obvio que, llegados a ese punto, la única insuficiencia de candidaturas que puede darse es la causada por el resultado de las comparecencias, esto es, la provocada por el hecho de que los candidatos admitidos por la Mesa no resulten, para la Comisión, acreedores de la confianza institucional del Senado, ante cuyo Pleno, por tanto, no se elevará una propuesta para su designación. La "suficiencia" es en ese caso también cuantitativa, pero la causa de tal insuficiencia no es la de no haberse presentado a la Mesa del Senado candidaturas autonómicas en número bastante para los puestos a cubrir, sino la no aceptación de las candidaturas por la Comisión de Nombramientos. "Candidaturas suficientes" es, por tanto, en este contexto, candidaturas de mérito suficiente y en número bastante para proveer a las designaciones que corresponda en cada caso realizar al Senado" (FJ núm. 9). 
por éstos no hayan "merecido su confianza en el trámite de la comparecencia o bien se producirá como consecuencia de que el Pleno del Senado no acepte alguna o todas las candidaturas propuestas por la Comisión" (FJ núm. 10).

Pero tal dificultad se expresa asimismo, y especialmente, cuando el Tribunal Constitucional se enfrenta a "una interpretación basada en el debate parlamentario que tuvo lugar en el proceso de elaboración y aprobación de la norma enjuiciada", dada una enmienda de supresión por la que expresamente se venía a negar la posibilidad de que la Comisión de Nombramientos pudiera presentar candidatos alternativos en caso de que los candidatos presentados no reunieran, a juicio de la Comisión, los requisitos exigidos ${ }^{54}$. A tales efectos, para el Tribunal "la pretendida voluntas legislatoris, derivada de los trabajos parlamentarios, no es la única y definitiva cuando se interpreta una norma", en particular en supuestos en los que, y como sucede en este caso, "se contrapondría con un entendimiento del precepto que lo hace conforme con las previsiones constitucionales"; y, por tanto, que haya de prevalecer la interpretación anteriormente expuesta, pues, "de acuerdo con un espíritu integrador y sistemático, resulta más razonable y es, además, conforme con la doctrina establecida en la STC 49/2008" (FJ núm. 10) ${ }^{55}$. Así, son los propios Senadores a los que finalmente les corresponde "elegir, mediante una votación secreta en la que los candidatos han de obtener la mayoría cualificada exigida constitucionalmente", a aquéllos que estimen "oportunos, de entre los juristas que aprecien que cumplen las condiciones constitucionalmente establecidas"; y consecuentemente, que ninguna objeción quepa formular a que el Senado "haya de limitarse, en principio, a elegir, como indica el art. 16.1 LOTC, entre los candidatos previamente presentados por las Asambleas Legislativas autonómicas", pues, y conforme se ha interpretado más arriba el artículo 184.7 del RS, se garantiza que el Senado pueda cumplir su función constitucional, «eligiendo a otros candidatos posibles surgidos de su propio seno, en el caso de que no resulte posible cubrir todos o alguno de los puestos de Magistrados del Tribunal Constitucional por no obtener la mayoría de

54 Cfr. Diario de Sesiones de la Comisión de Reglamento del Senado de 13 y de 21 de noviembre de 2007 .

55 "De esta forma, se evita el alegado riesgo de paralización del proceso de designación de Magistrados, pues este supuesto de frustración de las propuestas autonómicas, referido al concreto caso de que todos o alguno de los candidatos propuestos no alcance la cualificada mayoría necesaria para su nombramiento, sería uno de aquellos en los que, conforme a nuestra STC 49/2008 (FJ 9), "la remisión al Reglamento parlamentario no puede cerrar las puertas a que el propio Senado pueda velar por el ejercicio constitucionalmente correcto de su función". Se trataría, en suma, de situaciones en las que el órgano decisor debe, con arreglo a nuestra doctrina de la STC 49/2008, disponer de márgenes de maniobra para ejercer su indeclinable función constitucional. [...] Evitado así el riesgo de bloqueo del Senado en el ejercicio de su función, resulta que el propio Reglamento de la Cámara garantiza el mecanismo de la elección entre diversos candidatos, los cuales, además de cumplir con los requisitos establecidos, han de ser susceptibles de generar la confianza institucional necesaria respecto a su persona y méritos, expresado en la mayoría exigida para su designación" (FJ núm. 10). 
tres quintos los presentados por las Asambleas Legislativas de las Comunidades Autónomas" (FJ núm. 10) ${ }^{56}$.

Por otra parte, el parecer de la mayoría del Tribunal Constitucional resultó nuevamente contestado por otros tres Votos Particulares, a favor de la estimación del recurso de inconstitucionalidad; los de los Magistrados don Vicente Martín de Hijas, don Javier Delgado Barrio, y don Jorge Rodríguez-Zapata Pérez. En cuanto al primero de ellos, y en íntima conexión al anteriormente presentado con ocasión de la Sentencia 49/2008, el Magistrado discrepante considera el artículo 184.7 del RS como consumación procedimental de la vulneración que del artículo 159.1 y 2 de la Constitución venía ya a suponer el referido artículo 16.1 de la LOTC; y es que, según éste, la excepción que se recoge en el inciso final del artículo 184.7.b impide, finalmente, que el Senado "pueda elegir entre el amplio círculo de juristas definido en el art. 159.2 CE". Si bien la Sentencia 49/2008 "abría paso a la posibilidad de que el Reglamento del Senado pudiera habilitar mecanismos conducentes" para que el Senado así lo hiciera, la salvaguardia extrema de garantizar que éste pueda efectivamente hacerlo lleva ahora al Tribunal a "una interpretación conforme del art. 184.7 RS" jurídicamente inaceptable, en cuanto que "excede notoriamente de los límites que para ella se fijan" en la jurisprudencia constitucional al hacer "decir al precepto lo que en modo alguno dice, y sustituyéndolo en realidad por un precepto distinto ${ }^{57}$; y por tanto, que al igual que se hiciera en la anterior Sentencia, no se haya llegado con naturalidad a un "similar fallo desestimatorio, sin reservas", en vez de pronunciar un fallo interpretativo (según los términos de los FFJJ núms. 9 y 10, de la STC 101/2008). Con tal modo de razonar por el Tribunal, «bajo la afirmación apodíctica de que es obvio lo que se propone, se produce un indudable salto lógico, y una desfiguración del sentido del precepto".

Respecto al voto particular del Magistrado don Javier Delgado Barrio, éste asimismo remite a su anterior a la Sentencia 49/2008, de manera que la inconstitucionalidad del artículo 16.1 de la LOTC conduzca a la del artículo 184.7 del RS, en tanto que instrumento procedimental de aquél. Con todo, el Magistrado reconoce "el esfuerzo que la mayoría de [sus] compañeros ha

56 Termina así el Tribunal: "En mérito de lo expuesto, y así interpretado el precepto impugnado podemos apreciar que el Reglamento del Senado, cuyo contenido propio es el de regular, con sujeción a la Constitución, su propia organización y funcionamiento rigiendo el ejercicio de las competencias que corresponden a la Cámara, ha velado adecuadamente por el ejercicio constitucionalmente correcto de esta concreta función de designación atribuida a la Cámara, evitando tanto el riesgo de bloqueo en su ejercicio como que la misma pueda quedar vacía materialmente de contenido" (FJ núm. 10, in fine).

57 «...] deteniéndome por ahora en la relación entre la Sentencia precedente y la actual, estimo que ésta no se queda en el punto en que se quedó la anterior, sino que, avanzando en un discurso iniciado en ella, pero no reflejado en el fallo, convierte lo que en ésta se contempló como posibilidad hipotética de regulación por el Reglamento del Senado en condicionante implícito de la solución de la Sentencia precedente, pese a que en ella, como ya he indicado, no se hiciera reserva alguna en el fallo, si es que tal condicionante se hubiese considerado que debiera haberlo sido". 
hecho por encontrar un sentido al nuevo art. 184.7 RS que resulte ser conforme a la Constitución", haciendo posible "que el Senado elija los Magistrados del Tribunal Constitucional no entre los presentados por las Comunidades Autónomas, sino fuera de los que han sido propuestos". Pero ello a consta de una interpretación "contraria al inequívoco sentido normativo de la norma impugnada, que deriva inexorablemente de la finalidad, expresamente declarada, del art. 184.7 RS, de su tenor literal y del ostensible entendimiento que luce muy decisivamente en el debate parlamentario que dio vida al precepto aquí impugnado" ${ }^{58}$; y de este modo, que el Tribunal reconstruya "la norma recurrida", desfigurándola, y "creando" así "una norma nueva", asumiendo "una "función de legislador positivo" que desborda amplia y ostensiblemente el cometido institucional que la Constitución atribuye" a aquél.

Y por último, en relación al voto particular que formula el Magistrado don Jorge Rodríguez-Zapata Pérez (y una vez que recrea un hipotético voto a la anterior Sentencia 49/2008 en la que no participó, por cuanto que recusado ${ }^{59}$, éste sostiene que el artículo 184.7 del RS modifica las competencias constitucionales del Senado (art. 159.1 CE) y degrada su cualidad de órgano constitucional: "Nos encontramos ante una figura de acto compuesto [...] en la que la voluntad libre es la de cada Asamblea de Comunidad Autónoma y la voluntad vinculada la del Senado, ya que debe elegir "entre los candidatos" presentados por éstas". No obstante, lo anterior resultaría matizado según que se admita o no la libertad de aquél de rechazar las candidaturas presentadas por los Parlamentos autonómicos ("de no fácil comprensión"), y en particular si ello hubiere sido acompañado por una "flexibilidad y elasticidad de las normas que regulan el procedimiento de concurrencia de las voluntades que integran este nuevo acto compuesto" (en vez de la formalización y encorsetamiento extremo que supone la STC 101/2008 $)^{60}$; la Sentencia, según el Magistrado discrepante, termina por dibujar, "con un detalle sorprendente [...] un procedimiento de elección tan complicado que podría vulnerar la autonomía funcional de la Cámara Alta y

58 "[...] extender la "única" excepción prevista, que es la de la inexistencia de "candidaturas suficientes", "presentadas en plazo", como hace la Sentencia, a los casos en los que "no resulte posible cubrir todos o algunos de los puestos de Magistrado del Tribunal Constitucional por no obtener la mayoría de tres quintos los presentados por las Asambleas Legislativas de las Comunidades Autónomas", es, sencillamente, una manifiesta interpretación contra legem: el evidente espíritu de la nueva normativa - elección "entre"- conduciría en tales casos a sucesivas propuestas autonómicas. Muy lejos de ello, la Sentencia salva la constitucionalidad del precepto recurrido — que establece la necesidad de elegir "entre" - remitiendo a la decisión del Senado que su elección se produzca "entre" o fuera de las candidaturas autonómicas".

59 "Mi posición, debidamente explicada en las deliberaciones del Pleno, es simple: En la elección de los cuatro miembros de este Tribunal que corresponde al Senado la regulación constitucional es completa en lo sustantivo (art. 159.1 CE). No admite la posibilidad de concurso válido de ninguna otra norma de nuestro Derecho, que no sea el propio Reglamento, en lo procedimental".

60 Así, hubiera sido "más respetuoso con la libertad institucional insuprimible del Senado" el optar por una interpretación más abierta a la autonomía reglamentaria, "regida por la flexibilidad y el respeto a las reglas de juego que institucionalizan el debate político". 
los poderes de interpretación y de suplir lagunas de reglamento de su Presidente (art. 37.7 y 8 RS) ${ }^{61}$.

\section{III.C. Comentario CRítico de las Sentencias 49/2008 y 101/2008}

Respecto a la Sentencia 49/2008, ésta no presenta, a nuestro juicio, especiales dificultades; y ello en atención tanto a la propia posibilidad de que las Comunidades Autónomas puedan participar en el procedimiento de elección por el Senado de los cuatro Magistrados constitucionales que a éste le corresponde presentar a nombramiento real (art. 159.1 CE), conforme al vigente artículo 16.1 de la LOTC, como al alcance efectivo de dicha previsión. En cuanto a lo primero, de un lado, puesto que la configuración territorial del Senado (art. 69.1 CE) justifica constitucionalmente una interpretación sistemática que ampare la intervención de las Comunidades Autónomas en sus funciones y competencias (FJ 13), como, y de otro, por que tal intervención de las Comunidades en ningún caso desapoderaría al Senado de ser él quien efectivamente elija a los cuatro Magistrados constitucionales que le corresponde (FJ 14). Ciertamente, dicha dimensión territorial del Senado encuentra escaso eco expreso en la Constitución (arts. 69.5, 150.3, y 155.1 CE), pero ello no impide una lectura más abierta al respecto; al contrario, la justifica, sobretodo en atención al desarrollo que del Estado autonómico se ha vivido (más allá de las escuetas expectativas inicialmente previstas por el propio texto constitucional hace 30 años), y a la necesidad constitucional de integrar el pluralismo territorial y autonómico en la conformación política y jurídica del Estado en su totalidad ${ }^{62}$. Claro que al respecto resulta no ya conveniente, sino necesaria una reforma constitucional ${ }^{63}$, pero esto último no imposibilita interpretaciones y desarrollos de la Constitución que permitan, siempre dentro del marco constitucional, una cierta adecuación de la misma a la realidad y a las necesidades presentes, como es el caso que se comenta en estas páginas. Así, y concretando en dicho marco constitucional, cabe advertir como es constitucionalmente posible que en el Senado colaboren otros sujetos y órganos políticos siempre y cuando el núcleo de sus funciones y competencias

61 «El fallo, manipulativo y aditivo, que, a la postre, se impone a la Cámara (FFJ 9, 10 y fallo) por quien Sieyès habría considerado "une autorité étrangère", emplea la técnica italiana mas refinada en el siglo pasado para las sentencias interpretativas aditivas (Sentenze interpretative di rigetto di tipo additivo ovvero aggiuntivo)".

62 En relación a los Votos Particulares que acompañan a la STC 49/2008, no participamos así de la interpretación tan ajustada y literal que de la Constitución llevan a cabo los Magistrados discrepantes, pues terminan por encorsetar las posibilidades de alcanzar una mayor integración de la Comunidades Autónomas en la garantía constitucional del Estado autonómico en el que ellas participan, dado que integrantes del Estado mismo (art. $137 \mathrm{CE}$ ). En este sentido, también, M. CARRILLO, "Comentario a la STC 49/2008... cit., págs. 270 y 287 y ss.

63 Al respecto, por ejemplo, E. Aja, E. AlberTí Rovira ,J. J. Ruiz Ruiz, La reforma Constitucional del Senado, Centro de Estudios Políticos y constitucionales, Madrid, 2005. 
quede efectivamente garantizado ${ }^{64}$; y de este modo vendría a suceder en relación a la propuesta de candidatos a Magistrados constitucionales por los Parlamentos autonómicos, en cuanto que la elección definitiva de éstos quede efectivamente en manos del Pleno de aquél. Otra cosa es si se da adecuada garantía de ello, y que, en un pasó más, el Tribunal Constitucional advierta incluso de la necesaria garantía de que tal misión del Senado no sea entorpecida o frustrada por las Asambleas autonómicas; pero ello entra ya en el alcance y procedimentalización de dicha participación.

A estos efectos, la remisión que al RS contempla el artículo 16.1 de la LOTC difiere al referido RS (al tiempo, el vigente art. 184.7 RS) la constitucionalidad final de la propuesta que hayan/puedan hacer los Parlamentos autonómicos de candidatos al Senado para su ulterior elección por el Pleno de éste, en tanto que, conforme al RS, resulte adecuada y efectivamente garantizada dicha elección en manos del Senado de acuerdo a los requisitos expresamente establecidos en la propia Constitución (FJ núm. 9); y de esta forma, que buena parte del juicio de constitucionalidad del artículo 16.1 de la LOTC se difiera asimismo a un ulterior juicio sobre el RS (como así ha sucedido en atención a la STC 101/2008, según se ha presentado y se viene más adelante también a comentar ${ }^{65}$. Con tal reenvío, ya, se vendría a dar garantía parcial de la posición constitucional del Senado y del núcleo de su misión constitucional de elegir a cuatro Magistrados constitucionales por cuanto que es el propio Senado quien determinaría el grado de dicha participación autonómica; ahora bien, decimos que ello únicamente es garantía parcial por cuanto que, y como el propio Tribunal Constitucional entiende en su Sentencia 49/2008, ello no es disponible en su integridad por el Senado, al encontrarse constitucionalmente sujeto a la configuración institucional, funcional y competencial que del mismo hace directamente la Constitución; y por esto que el Tribunal entienda que el Senado, finalmente, quede obligado a ofrecer adecuada garantía de que el núcleo de la elección de los Magistrados constitucionales resulte efectivamente en manos de él (FFJJ núm. 10 y 11), para lo cual, además, plantea, no obstante, un abanico abierto de posibilidades (FJ 14, nuevamente).

Con ello, a su vez, viene a encauzarse ante el Tribunal Constitucional otra tacha de constitucionalidad referida al sistema de fuentes del Derecho, en tanto que relativa a la reserva de reglamento parlamentario (art. $72.1 \mathrm{CE}$ ), y al propio exceso que de la reserva de ley orgánica supone (según los recurrentes) el vigente artículo 16.1 de la LOTC (arts. 81 y $165 \mathrm{CE}$ ). Al respecto, sin embargo (según el Tribunal), el artículo 16.1 de la LOTC no sólo supone un desarrollo de la regulación de la composición del Tribunal Constitucional en relación con el Senado, sino que además prevé la intervención de órganos ajenos al mismo (los Parlamentos autonómicos), lo que queda fuera de la re-

64 En torno al principio de división de poderes como distinción y colaboración entre los mismos, cfr. J. F. SÁnchez BARRILAO, Las funciones no jurisdiccionales de los jueces en garantía de derechos, Civitas, Madrid, 2002, págs. 44-46 (y la bibliografía allí citada).

65 Vid. asimismo A. L. SANZ Pérez, "Comentario a la STC 49/2008 ... cit., págs. 7 y 8. 
serva del $\mathrm{RS}^{66}$; pero a la par remite la concreta procedimentalización y alcance de la participación autonómica en la elección de los Magistrados constitucionales que corresponde elegir al Senado a lo que establezca su propio Reglamento parlamentario, salvándose de este modo, también, la reserva de RS (FFJJ núms. 15 y 16) ${ }^{67}$. Así, que estemos ante una situación de asistencia normativa, dado que ambas fuentes concurren materialmente en su respectivo espacio material colaborando en una regulación conjunta y coetánea; y por tanto, que ninguna de ellas, por separado y aisladamente, sea capaz legítimamente de prever normativamente la participación de los Parlamentos autonómicos en la elección por el Senado de los cuatro Magistrados constitucionales que a éste le corresponde ${ }^{68}$.

Mayores dudas, en cambio, nos plantea la Sentencia 101/2008; dudas que, por otra parte, encuentran su razón última en la forma que el artículo 184.7 del RS ha dado desarrollo efectivo al alcance y a la procedimentalización de la participación de los Parlamentos autonómicos en la elección de los cuatro Magistrados constitucionales que a éste le conciernen, según se viene a mostrar.

La Sentencia se presenta, en principio, como una extensión lógica de la anterior 49/2008, en atención al reenvío del artículo 16.1 de la LOTC al RS, conforme se ha tenido ocasión de comentar (así, FJ núm. 3), y por tanto que, finalmente, sea en la Sentencia 101/2008 donde el Tribunal termine por dilucidar la constitucionalidad de la participación autonómica en la composición de éste; pero ello no en relación a su justificación y posibilidad constitucional, puesto que resuelto ya en la Sentencia 49/2008, sino a cómo se ha llevado normativamente a término por el artículo 184.7 del RS (FJ núm. 4). En este sentido, el Tribunal analiza tres aspectos, todos ellos en íntima conexión con la obligación del Senado de cumplir su función constitucional de elegir efectivamente a cuatro de los Magistrados constitucionales (conforme se apuntara ya en la STC 49/2008, según se ha visto).

El primero de ellos estriba en como la elección definitiva por el Senado ha de cumplir con los requisitos constitucionalmente exigidos en relación a la

66 También, I. Torres Muro, «La reforma de la Ley Orgánica del Tribunal Constitucional... cit., págs. 9 y 12.

67 Y con ello, los problemas de constitucionalidad que habíamos advertido con ocasión de otras propuestas de reforma de la LOTC al respecto, en las que no se hacía referencia alguna al RS, mientras que, sin embargo, sí preveían expresamente la intervención de la Comisión General de las Comunidades Autónomas.

68 Colaboración normativa entre reglamento parlamentario y ley orgánica que no es nueva, como así sucediera, en cierto modo, con ocasión del procedimiento articulado en relación con la propuesta por el Congreso de los Diputados y por el Senado de los doce vocales judiciales del Consejo General del Poder Judicial, conforme LO 2/2001, de 28 junio, en atención a una propuesta previa de dichos vocales por los propios jueces y magistrados (art. 122.3 CE): art. 112 LOPJ (modificado por art. único LO 2/2001 de reforma LOPJ); art. $205.2 \mathrm{RC}$ (apartado añadido por reforma del RC, de 27 de junio de 2001); y art. 184.6 RS (apartado introducido por reforma del RS, de 27 de junio de 2001). Así, la propia STC 49/2008 (FJ núm. 14). No obstante, decimos en cierto modo por cuanto que en este supuesto ni la intervención del Congreso ni del Senado viene exigida constitucionalmente (como en cambio sí se da respecto a los vocales no judiciales). 
condición de Magistrado constitucional (art. 159.2 CE), y ello respecto tanto a la propuesta que hayan de hacer, en su caso, los Parlamentos autonómicos, como a la propuesta definitiva que el Senado ha de elevar al Rey, lo que supone, esto último, un juicio de valor definitivo por parte del propio Senado; esto, a su vez, conlleva que inicialmente los Parlamentos autonómicos deban acreditar el cumplimiento por los candidatos que proponen de tales requisitos, y que la Mesa del Senado pueda no admitir dichas propuestas respecto a aquellos candidatos que a su entender (y previa consulta a la Comisión de Nombramientos) no los cumplan, sin perjuicio de que los Parlamentos puedan presentar nuevos candidatos dentro del plazo establecido por la Mesa (conforme art. 184.3, 4 y 7 RS). Mas todo ello, recalca el Tribunal (y de acuerdo a lo adelantado más arriba), sin que se garantice que tales candidatos sean finalmente elegidos por el Pleno del Senado (FJ núm. 5). Con esto, ya, la Sentencia sienta las bases de una potencial desconexión entre la propuesta de los Parlamentos autonómicos y de la elección final del Senado de los Magistrados constitucionales, de acuerdo a la garantía constitucional del núcleo de las funciones y competencias de éste (según se ha comentado con ocasión de la STC 49/2008); y ello, por ahora, desde un oportuno equilibrio, a nuestro entender, entre la posibilidad que se abre a que las Comunidades Autónomas puedan presentar candidatos a Magistrados constitucionales y la garantía constitucional de que los Magistrados definitivamente elegidos cumplan con los requisitos constitucionales que se les exige a juicio del propio Senado.

La segunda cuestión, y en un paso más allá, hace referencia ahora a la propuesta que ha de presentar la Comisión de Nombramientos del Senado al Pleno del mismo, con tantos candidatos como puestos a cubrir; y esto, tras la necesaria comparecencia de los candidatos inicialmente propuestos por los Parlamentos autonómicos en dicha Comisión, de acuerdo a los artículos 184.7.b del RS y 16.2 de la LOTC ${ }^{69}$. En relación a tal comparecencia, a su vez, el Tribunal Constitucional destaca su carácter obligatorio, con lo que resulta lógico entender, como hace el Tribunal, que la no comparecencia de aquéllos conlleve que éstos no puedan ser incluidos en la propuesta que eleve la Comisión al Pleno; pero también adelanta el Tribunal que tal comparecencia tiene por fin permitir a la Comisión realizar un examen de la idoneidad de los precandidatos conforme a los requisitos constitucionales exigidos a los mismos, como al potencial y ulterior juicio a realizar por el Pleno al respecto. Y todo ello, además (recalcando nuevamente el Tribunal), sin que el Pleno del Senado se vea obligado a aceptar la propuesta de su propia Comisión de Nombramientos (FJ núm. 6). Con esto el Tribunal Constitucional centra definitivamente su pronunciamiento en torno al artículo 184.7 del RS, pues prepara la posibilidad de que la Comisión presente al Pleno una propuesta dis-

69 Vigente art. 16.2 LOTC, asimismo conforme a LO 6/2007, según se ha señalado (art. úni$\mathrm{co}$, apartado $7 .^{\circ}$ ); sin embargo este precepto no fue objeto de recurso de inconstitucionalidad alguno, cuando también incide en la actuación interna del Congreso de los Diputados, como del Senado (según se está viendo). 
tinta de las inicialmente presentadas por los Parlamentos autonómicos (la parte más problemática de la STC 101/2008, a nuestro parecer); mas esto, todavía dentro de la lógica de cualquier propuesta ordinaria de candidatos a elevar por la Comisión de Nombramientos al Pleno del Senado en relación a cualesquiera nombramiento llamado éste a realizar constitucionalmente conforme a los artículos 184 a 186 del RS, pues el Pleno siempre será el llamado constitucionalmente a decidir definitivamente al respecto ${ }^{70}$. No en vano, resulta más oportuno que el disenso entre las propuestas y la voluntad del Senado se constate a nivel de Comisión, que ya en el Pleno; y consecuentemente, en principio, que resulte conveniente que se intente salvar tal situación en el marco más contenido e integrador de la labor de aquélla, que en la más abierta y definitiva de éste, dada su mayor transcendencia pública y política.

Y la tercera y decisiva cuestión es que la Comisión de Nombramientos, de acuerdo a lo adelantado más arriba, pueda, llegado el caso, plantear al Pleno candidatos distintos a los inicialmente propuestos por los Parlamentos autonómicos a modo de cláusula de cierre a fin de garantizar que el Senado lleve a cabo su función constitucional de elegir cuatro de los doce Magistrados constitucionales; y tal caso se daría cuando la Comisión estimara que los candidatos prepropuestos no habrían de alcanzar la mayoría requerida en el Pleno (FJ núm. 7). Esto, por su parte, no sería un mero juicio hipotético de la Comisión de Nombramientos sobre lo que pueda resolver el Pleno, sino una evaluación previa de lo que los Grupos Parlamentarios puedan plantear a sus miembros ya en el Pleno, en tanto que la Comisión de Nombramientos está presidida por el Presidente del Senado e integrada precisamente por los Portavoces de aquéllos, a la par que adopta sus acuerdos en función del criterio del voto ponderado (art. 185.1 y 2 RS). Claro está, ello contradice el criterio de los recurrentes, quienes sostienen la imposibilidad de que la Comisión pueda realizar tal juicio, por cuanto que se encuentra sujeta a las propuestas de las Comunidades Autónomas, y que en última instancia el Pleno tenga que elegir asimismo "entre" dichos candidatos ${ }^{71}$.

A estos efectos, el Tribunal Constitucional advierte la posibilidad expresa que brinda el propio artículo 184.7.b del RS para el supuesto en que los Parlamentos autonómicos no propongan tantos candidatos como puestos a cubrir, de modo que la Comisión de Nombramientos realice una propuesta

70 Obviamente de tal procedimiento ordinario habría que excluir la elección por el Senado de los seis vocales judiciales integrantes del Consejo General del Poder Judicial que a éste le corresponde (conforme arts. 112 LOPJ y 184.6 RS, según se ha señalado), en atención a su atribución ahora meramente legal (LO 2/2001), que no constitucional; otra cosa es, nuevamente, respecto a los cuatro vocales no judiciales a designar por el Senado, en tanto que ahora sí previsto constitucionalmente (art. 122.3 CE).

71 Tal entendimiento nos recuerda, en exceso, al supuesto anteriormente señalado en nota con relación a la elección de los vocales judiciales del Consejo General del Poder Judicial por el Senado, dado que ésta habrá de hacerse entre los propuestos por los propios jueces y magistrados; pero es que en este caso, recuérdese, tal función del Senado no viene prevista por la Constitución, sino por norma legal (aun orgánica), con lo que se atenuaría la disponibilidad constitucional de dicha elección por el Senado. 
propia a fin, siempre, de garantizar la elección de los cuatro Magistrados constitucionales por el Pleno del Senado; pero también, ahora, para el caso en que, como se ha adelantado, la Comisión apreciara que algunos o todos los candidatos propuestos por los Parlamentos autonómicos no alcanzaran los requisitos exigidos (FJ núm. 8). Es a partir de este momento cuando comienzan los aspectos más discutibles de la Sentencia, según se viene a mostrar.

De un lado, y partiendo del principio de conservación de la norma, el Tribunal afronta la necesidad de una interpretación del artículo 184.7 del RS que garantice el libre juicio que de la idoneidad de los candidatos está llamado a hacer el Pleno del Senado desde un criterio de "estricta discrecionalidad política", a la vez que evite un estancamiento de la efectiva elección por el Senado de los cuatro Magistrados constitucionales que le corresponde. Y así que no quepa realizar una interpretación literal ahora del artículo 184.7.b del RS, de forma que por falta de candidatos se entienda no sólo su acepción numérica, sino también otra de tipo "cualitativo o de mérito" que incluya el que los candidatos puedan finalmente recibir el apoyo del Pleno (FJ núm. 9).

Y de otro lado, y sin embargo, que el propio Tribunal Constitucional sea consciente de la dificultad de tal interpretación, en especial a la vista del proceso de elaboración y aprobación del artículo 184.7 del RS (según se ha señalado), conforme al cual vendría a justificarse que la elección por el Pleno se limitara a los candidatos efectivamente presentados por los Parlamentos autonómicos, de modo que la Comisión de Nombramientos sólo podría presentar candidatos en caso de que las propuestas autonómicas no alcanzaran los puestos a cubrir. Al respecto, el Tribunal justifica separarse de la voluntas legislatoris, dada la disponibilidad última de dichas propuestas en manos del Pleno del Senado, de manera que resulte garantizada su función constitucional de elegir a cuatro Magistrados constitucionales.

Al respecto, no cuestionamos en ningún modo que el Pleno del Senado pueda decidir definitivamente sobre la idoneidad de los candidatos que le eleve la Comisión de Nombramientos, ni que la propia Comisión, a los efectos de la preparación de la propuesta que ha de elevar al Pleno, pueda ya evaluar dicho juicio del Pleno sobre la idoneidad de los Magistrados constitucionales a elegir por el Senado; ni por último el que, llegado el caso, pueda la Comisión de Nombramientos proponer candidatos alternativos a los presentados por los Parlamentos autonómico no ya sólo por que no haya numéricamente candidatos suficientes, o por que a discernimiento de la Mesa y la propia Comisión éstos no cumplan los requisitos objetivos constitucionalmente exigidos a los mismos (art. 159.2 CE), sino por que, e incluso, entienda que tales candidatos no van finalmente a superar el juicio de idoneidad del Pleno del Senado. No en vano, lo que se pretende con este procedimiento, y conforme se ha mostrado en las primeras páginas de este texto, es sencillamente procurar un mecanismo de integración del interés que poseen las Comunidades Autónomas en la composición del Tribunal Constitucional con ocasión de la elección por el Senado de cuatro de los Magistrados constitucionales, y a fin de postular que en tal elección se conjuguen diversas sensibilidades en relación 
a la ordenación constitucional del Estado autonómico; ello, a nuestro entender, vendría a alcanzarse inicialmente con la posibilidad que se brinda a los Parlamentos autonómicos de que presenten candidatos a tales efectos.

Pero otra cosa es la concreta interpretación que del artículo 184.7.b del RS hace el Tribunal Constitucional en tanto que no postula una mera interpretación posible del precepto, pues viene a tasar la misma, al condicionar a ella la constitucionalidad del artículo recurrido ante él; y ello sin dejar maniobra alguna, no sólo en relación a una posible y ulterior intervención de los Parlamentos autonómicos, sino al propio Senado a la hora de buscar una hipotética salida satisfactoria en el supuesto de que la Comisión de Nombramientos advierta que alguno de los candidatos propuestos por aquéllos, aun cumpliendo los requisitos objetivos exigidos constitucionalmente, no van, sin embargo, a superar el juicio de idoneidad del Pleno del Senado, y por tanto la Comisión se encuentre sin candidatos factibles con los que elevar al Pleno su propuesta de cuatro Magistrados. En tal sentido, el propio Tribunal en su anterior Sentencia 49/2008 había advertido (si bien en relación al art. 16.1 LOTC) como no iba a hacer un juicio de perfección de la norma (FJ núm. 4), a la par que adelantaba un potencial abanico de posibilidades del RS en relación con la necesaria garantía constitucional de que el Senado cumpla efectivamente su cometido constitucional de elegir a cuatro de los Magistrados constitucionales $^{72}$; y ello, recordemos, dada la consideración instrumental del RS en la concreción del alcance y la procedimentalización de la intervención de las Asambleas Legislativas de las Comunidades Autónomas en el proceso de elección de los cuatro Magistrados que a aquél le corresponde (FFJJ núms. 14 y 15 ${ }^{73}$. Es más, en la propia Sentencia 101/2008 se plantea incluso que, para salvar tal situación, fueran los propios Grupos Parlamentarios los que presentaran los candidatos a Magistrados a partir de las propuestas previamente formuladas por los Parlamentos autonómicos (según el Abogado del Estado, en Antecedente 5, in fine); sin embargo esto fue expresamente rechazado por el Tribunal, no por "imposible», sino por considerar más lógica la otra opción (FJ núm. 5) $7^{74}$.

72 Abanico que, suponemos, habría hecho el Tribunal a la vista de la reforma ya aprobada, en aquel momento, del art. 184.7 RS.

73 Nuevamente, “[d]e lo expuesto cabe deducir, entre otros extremos, que el tenor literal del art. 16.1 LOTC permite que el Reglamento del Senado pueda, entre otras fórmulas, prever, incluso, mecanismos que hagan posible que sea la propia Cámara la que proponga candidatos a Magistrados del Tribunal Constitucional en el supuesto excepcional de que el sistema de elección de dichos Magistrados previsto con carácter general no culmine con esta elección, garantizando así que la Cámara Alta cumpla con su obligación constitucional" (STC 49/2008, FJ núm. 14, in fine). Y además, «[clomo se ha señalado anteriormente, los términos en que está redactado el precepto impugnado dejan abiertas diversas posibilidades que no nos corresponde analizar en este proceso. Pero además desde el punto de vista del sistema de fuentes, una norma que remite a los Reglamentos parlamentarios la concreción de un principio participativo que, como se ha visto, es constitucional, tampoco puede considerarse contraria al art. $72.1 \mathrm{CE}$ si, como es el caso, deja abierta diversas posibilidades para realizar dicho desarrollo" (FJ núm. 15, in fine).

74 «[...] la afirmación del Abogado del Estado según la cual los candidatos serían presentados por los grupos parlamentarios del Senado a partir de los previamente propuestos en sede au- 
Es de esta forma que el Tribunal Constitucional reduzca finalmente las posibilidades interpretativas del artículo 184.7.b del RS, viniendo a condicionar indefectiblemente la propia autonomía del Senado, y con ello una hipotética comunicación de éste con las Comunidades Autónomas a los efectos de la determinación por la Comisión de Nombramientos de los cuatro candidatos a elevar al Pleno. Admitiendo que el artículo 184.7 no limita la plena disponibilidad del Senado en su función constitucional de elegir cuatro Magistrados constitucionales, y que la Comisión de Nombramientos podría llegado el caso rechazar las propuestas de los Parlamentos autonómicos, cabría aceptar que sólo en el supuesto de que efectivamente así se diera (de manera que la Comisión no dispusiera de cuatro candidatos efectivos suficientes para elevar al Pleno del Senado), se evidenciaría una laguna en tal procedimiento; laguna, a su vez, a resolver por el mismo Senado conforme al artículo 37.8 del RS, pudiendo éste decidir autónomamente tanto a favor de la interpretación que ofrece el Tribunal Constitucional en su Sentencia 101/2008, como por otra (por ejemplo, dando oportunidad a los Parlamentos autonómicos interesados a que en un breve plazo de tiempo hicieran nuevas propuestas), siempre y cuando, eso sí, quedara garantizada la función constitucional del Senado de elegir los cuatro Magistrados constitucionales (nuevamente art. 159.1 CE, y naturalmente la propia STC 101/2008, hasta su FJ núm. 9). A estos efectos, en general, no se ha de olvidar la consideración normativa que se tiene de tales resoluciones supletorias e integrativas, al mismo nivel de fuentes del Derecho que los propios reglamentos parlamentarios y susceptibles, incluso, de control de constitucionalidad por el Tribunal Constitucional; y en este orden, de manera particular, la posibilidad misma de que dichas resoluciones puedan regular aspectos relativos al procedimiento de elección de sujetos a cargo de las Cámaras parlamentarias (como así ha sucedido con ocasión de la creación de la Comisión Consultiva de Nombramientos del Congreso de los Diputados mediante Resolución de la Presidencia del Congreso de 25 de mayo de 2000) ${ }^{75}$. Pero es que, además, la Sentencia 101/2008, dada su estricta interpretación, cabría llegar a limitar la propia potestad reglamentaria del Senado en relación a una potencial reforma parcial del artículo 184.7 del RS, conforme a la cual viniera hipotéticamente a establecerse una procedimentalización diversa de la establecida por la STC 101/2008 (nuevamente, por ejemplo, dando oportuni-

tonómica, si bien no es una interpretación imposible del precepto, más lógico es pensar que dicha propuesta ha de hacerse directamente al Senado desde las Asambleas Legislativas de las Comunidades Autónomas y, consecuentemente, que la carga de acreditar de forma indubitada que los candidatos cumplen los requisitos exigidos para desempeñar el cargo ha de pesar sobre aquéllos que los proponen, es decir, las Asambleas autonómicas" (STC 101/2008, FJ núm. 5).

75 De interés, E. JeRónimo SÁnchez-BEATo, "La "Comisión Consultiva de Nombramientos del Congreso de los Diputados". Algunas reflexiones a propósito de la Resolución de la Presidencia del Congreso de 25 de mayo de 2000", CORTS. Anuario de Derecho Parlamentario, núm. 11, 2001, especialmente págs. 161 y ss.; y con carácter general, sobre las resoluciones interpretativas y supletorias de los reglamentos parlamentarios, y su control constitucional, vid. el reciente trabajo de E. Gómez Corona, La autonomía parlamentaria en la práctica constitucional española, Tirant lo Blanch, Valencia, 2008, págs. 89 y ss. (y la bibliografía allí citada). 
dad a los Parlamentos autonómicos interesados a que en un breve plazo de tiempo hicieran nuevas propuestas), por cuanto que dicha reforma debería garantizar absolutamente cualquier posible obstruccionismo de aquéllas ${ }^{76}$.

Se evidencia así un empeño del Tribunal Constitucional por que se garantice, frente a cualquier forma de potencial obstruccionismo, una pronta elección por el Senado de los cuatro Magistrados constitucionales que éste ha de proponer a nombramiento real ${ }^{77}$. Obviamente resulta comprensible dicho empeño con carácter abstracto, en atención a las graves dificultades que conlleva la falta de acuerdo en la elección de los Magistrados constitucionales correspondientes a las Cortes Generales y la prorrogatio de los Magistrados salientes en sus funciones mientras esto se resuelve ${ }^{78}$; pero lo que no entendemos es que se concentre tal grado de garantía frente al obstruccionismo respecto a las Comunidades Autónomas (hasta ahora sólo hipotético), cuando son hoy las actitudes de los grupos parlamentarios la mayor fuente de los problemas que se plantean en relación a una pronta y oportuna renovación de la composición del Tribunal Constitucional ${ }^{79}$. Es de esta forma que se deslice por el Tribunal una sospecha en relación con la potencial actuación de las Comunidades Autónomas al respecto, lo que, desde luego, va en contra de la idea misma de integración que las reformas de los artículos 16.1 de la LOTC y 184.7 del RS inicialmente pretendían.

Con esto es, finalmente, que nos preguntemos por cuál haya sido la razón que ha llevado al Tribunal Constitucional a variar su parecer de la Sentencia 49/2008 a la 101/2008 (más allá de la fundamentación jurídica que ofrece el propio Tribunal). En tal sentido resulta objetivo, de un lado, la distinta composición del Tribunal Constitucional en su primer pronunciamiento fren-

76 Ciertamente, con esta crítica, parecería compartirse, ahora, parte de los postulados presentados por los Votos Particulares a la STC 101/2008; no obstante, se ha de señalar que no participamos de tales Votos, por cuanto que éstos, si bien recogen la contradicción que resulta entre las SSTC 49/2008 y 101/2008, lo hacen, desde su inicio, manteniendo una postura cerrada a la posibilidad de que las Comunidades Autónomas puedan participar en la elección por el Senado de cuatro de los doce Magistrados constitucionales (por más que, y sin embargo, dichos Votos Particulares admitan puntualmente cierto grado de colaboración, lo que les lleva a entrar en tanta contradicción interna como la que, finalmente, critican a la mayoría).

77 No en vano, la STC 101/2008 ha venido a coincidir en el tiempo con una renovación parcial de los miembros Tribunal Constitucional, y en especial de aquéllos que han de ser elegidos por el Senado.

78 Otra cosa es que en este momento, además, se esté a la espera de la resolución definitiva del recurso de inconstitucionalidad del nuevo Estatuto catalán, y la incidencia negativa que en la composición del Tribunal Constitucional tal recurso ya ha originado.

79 Como se pone asimismo en evidencia en relación con la elección que corresponde al Congreso de los Diputados del Magistrado que ha de sustituir al Magistrado fallecido don Roberto García-Calvo y Montiel (18/5/2008), dado que perteneciente al cupo del Congreso, o a los propios Magistrados a elegir por el Senado, una vez presentadas las propuestas por los Parlamentos autonómicos (a fecha de elaboración de estas páginas). Al respecto de los retrasos en el nombramiento de los Magistrados constitucionales, vid. por ejemplo J. GARCía ROCA, "La experiencia de veinticinco años de jurisdicción constitucional en España", en AAVV La reforma del Tribunal Constitucional... cit., págs. 46-49. 
te al segundo ${ }^{80}$, como, y de otro lado, las distintas mayorías alcanzadas a la postre $^{81}$. Es por ello que podamos conjeturar un proceso de acercamiento de posiciones entre unos y otros Magistrados a fin de alcanzar una segunda Sentencia más unánime, salvando discrepancias ${ }^{82}$, y con la que el Tribunal vendría a presentarse con un mayor grado de acuerdo (lo que mejoraría su proyección externa, bastante devaluada en los últimos tiempos). Obviamente, esto resulta claramente positivo, mas con el precio de un cambio de parecer muy reciente, en exceso restrictivo y no suficiente argumentado en la Sentencia 101/2008.

\section{CONSIDERACIONES FINALES}

Al hilo del comentario ofrecido, son varias las cuestiones que quedan abiertas con ocasión de las Sentencias 49/2008 y 101/2008 en relación a la constitucionalidad de los nuevos artículos 16.1 de la LOTC y 184.7 del RS; de ellas, a nuestro entender, destaca la ausencia de la Comisión General de las Comunidades Autónomas en el procedimiento previsto a fin de integrar las Comunidades Autónomas en la elección por el Senado de los cuatro Magistrados que constitucionalmente le corresponde. Y es que la hipotética inclusión de dicha Comisión (de acuerdo a las propuestas normativas al respecto presentadas en el pasado) posiblemente hubiera permitido una mayor flexibilidad en la intervención de las Comunidades en la elección por el Senado de los Magistrados constitucionales (antes del Pleno), lo que a su vez hubiera potenciado más la comunicación e integración de éstas en la formación de la

80 STC 49/2008: don Vicente Conde Martín de Hijas, don Javier Delgado Barrio, doña Elisa Pérez Vera, don Eugeni Gay Montalvo, don Ramón Rodríguez Arribas, don Pascual Sala Sánchez, don Manuel Aragón Reyes y don Pablo Pérez Tremps (y de otra parte, y según se ha señalado, advirtiéndose la abstención de doña María Emilia Casas Baamonde y don Guillermo Jiménez Sánchez, además de la recusación de don Roberto García-Calvo y Montiel y don Jorge Rodríguez-Zapata Pérez). Y STC 101/2008: doña María Emilia Casas Baamonde, don Guillermo Jiménez Sánchez, don Vicente Conde Martín de Hijas, don Javier Delgado Barrio, doña Elisa Pérez Vera, don Jorge Rodríguez-Zapata Pérez, don Ramón Rodríguez Arribas, don Pascual Sala Sánchez, don Manuel Aragón Reyes y don Pablo Pérez Tremps (además, se ha de señalar el fallecimiento, ya apuntado, de don Roberto García-Calvo y Montiel).

81 Conforme se ha indicado, el parecer mayoritario del Tribunal en su STC 49/2008 resultó contestado por tres Votos Particulares; eran los de los Magistrados don Vicente Martín de Hijas, don Javier Delgado Barrio, y don Ramón Rodríguez Arribas. Mientras que en la STC 101/2008, los Votos Particulares corrieron a cargo de don Vicente Martín de Hijas y don Javier Delgado Barrio, nuevamente, y don Jorge Rodríguez-Zapata Pérez, ahora. Es evidente así cómo el Magistrado don Ramón Rodríguez Arribas pasa en la STC 101/2008 a formar parte de la mayoría del Tribunal, además de ser él, precisamente, el Ponente de la misma (Antecedente núm. 7).

82 Como parece hacer referencia el Magistrado don Javier Delgado Barrio al comienzo de su Voto Particular a la STC 101/2008: “Independientemente de lo expuesto, he de reconocer el esfuerzo que la mayoría de mis compañeros ha hecho por encontrar un sentido al nuevo art. 184.7 RS que resulte ser conforme a la Constitución, es decir, para hacer posible que el Senado elija los Magistrados del Tribunal Constitucional no entre los presentados por las Comunidades Autónomas, sino fuera de los que han sido propuestos". 
voluntad del mismo; en cambio, el sistema actual, y al amparo de la doctrina que contempla la Sentencia 101/2008, reduce tal flexibilidad e integración, aproximándose finalmente al procedimiento hasta ahora vigente.

Por otra parte, está cómo se desarrolla el propio proceso, aun abierto (en el momento de elaboración de este trabajo), de elección de los Magistrados constitucionales por el Senado (según los vigentes arts. 16.1 LOTC y 184.7 $\mathrm{RS}$ ). Al margen de la influencia que al respecto (y en el futuro) tenga la recusación del Magistrado Pablo Perez Tremps (ATC 26/2007, de 5 de febrero) en la idoneidad de los candidatos ${ }^{83}$, están los pactos a los que los dos grandes partidos políticos a nivel nacional parecen haber llegado (de acuerdo a las noticias que se vienen publicando en los medios de comunicación) en relación con las propuestas realizadas por los Parlamentos autonómicos; un proceso, así, que lejos de aportar un mayor grado de integración de las Comunidades Autónomas en la elección de los Magistrados constitucionales, se asemejaría en definitiva a lo que hasta hace poco se venía dando (nuevamente) ${ }^{84}$.

En este sentido, no se comprende el esfuerzo y el coste político que han supuesto dichas reformas normativas, cuando finalmente la participación e integración de las Comunidades Autónomas en la elección por el Senado de los cuatro Magistrados del Tribunal Constitucional parece resultar más formal que real. Y todo esto, aún más, a la vista de cómo las Sentencias 49/2008 y 101/2008 (al margen de la doctrina constitucional ofrecida, y comentada)

83 Con ello nos referimos a la idoneidad que para la condición de Magistrado del Tribunal Constitucional supone el que miembros del mundo académico, además de otros juristas, se hayan distinguido, al hilo de su actividad intelectual e investigadora, en cuestiones de la máxima relevancia constitucional, de manera que éstos, lejos de presentarse como candidatos idóneos, han pasado a ser considerados como sujetos potencialmente problemáticos a la hora de enjuiciar dichas cuestiones. Al respecto, vid.: L. E. Delgado Del Rincón, "La recusación de los Magistrados del Tribunal Constitucional (Comentario al ATC 26/2007, de 5 de febrero)", Revista Española de Derecho Constitucional, núm. 82, 2008, págs. 347-394; T. JEFFREY MiLEY, Recusal and the Question of Judicial Independence: Reflections on the Current Spanish Controversy in Comparative and Theoretical Perspective, Centro de Estudios Políticos y Constitucionales, Madrid, 2008, en http://www.cepc.es/working.asp (15/01/2009); y en especial E. GuILLÉN LÓPEz, "Judicial Review in Spain: The Constitutional Court", Loyola Law Review, núm. 41/2, 2008, págs. 536 y 537.

84 Así, en relación al Abogado del Estado en sus alegaciones al recurso de inconstitucionalidad núm. 6729-2007: "Tras recordar los preceptos del Reglamento del Senado que regulan la elección de los miembros del Tribunal Constitucional, el representante del Gobierno señala que en el momento de entrar en vigor la reforma impugnada el derecho de presentación de candidatos se atribuye a los grupos parlamentarios de la Cámara Alta, lo cual, desde un punto de vista de la sociología política, quiere decir que son las direcciones de los partidos y fuerzas políticas con representación parlamentaria los que realmente ejercen tal derecho a través de los grupos parlamentarios. Con la reforma recurrida la titularidad inicial del derecho de presentación de candidatos a Magistrado pasa a corresponder a las Asambleas autonómicas en exclusiva, aunque desde un punto de vista de sociología política no resulte difícil predecir que serán las direcciones de los dos grandes partidos estatales las que, a través de sus parlamentarios en las distintas Comunidades Autónomas, podrán seguir proponiendo a los candidatos que consideren oportunos" (STC 49/2008, Antecedentes núm. 9.c). De "paripé» incluso llega a hablar I. Torres Muro al respecto de las reformas de la LOTC y del RS, en "La reforma de la Ley Orgánica del Tribunal Constitucional... cit., págs. 24 y 25. 
han vuelto a evidenciar la ruptura y el enfrentamiento en el seno del Tribunal Constitucional. Al respecto de esto último, y sólo en relación con la Sentencia 49/2008, está, además de la referida abstención de la Presidenta y del Vicepresidente del Tribunal Constitucional, la recusación aceptada de otros dos Magistrados del mismo a instancia del Gobierno, de manera que el Pleno del Tribunal quedó reducido a su composición mínima de ocho miembros (art. 14 LOTC $)^{85}$; luego, también, están los tres Votos Particulares tanto a la Sentencia 49/2008, como a la 101/2008 (de los que se ha dado cuenta). Ello, en absoluto, cuestiona la legitimidad de ambos pronunciamientos, pero sí que, desde luego, incide en la visión que del Tribunal Constitucional se tiene, en particular ante los procesos constitucionales abiertos en relación con las últimas reformas estatutarias aprobadas y la misión integradora a desarrollar por el Tribunal con ocasión del conflicto en el seno del Estado autonómico; y por tanto, en el alcance integrador que se presume y justificaría el propio proceso de participación de las Comunidades Autónomas en la propuesta por el Senado de cuatro de los Magistrados constitucionales a nombrar por el Rey.

Ambas Sentencias, así, evidencian un nuevo episodio de ruptura de la colegialidad que ha de presidir la actuación de los miembros del Tribunal Constitucional $^{86}$, y que últimamente se encuentra en entredicho en nuestro país; una colegialidad que, aun inserta de un fundamento de pluralismo (y por tanto, sin que en ningún momento suponga unanimidad o uniformidad de parecer $)^{87}$, es necesaria a fin de que el Tribunal Constitucional pueda presentarse como garante último de la Constitución y de la unidad que ésta representa y supone para mayorías y minorías. Naturalmente, ello no es responsabilidad exclusiva de los miembros del Tribunal Constitucional, sino también de las diversas fuerzas políticas al trasladar sus enfrentamientos políticos al seno mismo del Tribunal, la más de los casos desde una perspectiva estrecha y efímera en post del rédito político, en vez del más general y permanente del interés constitucional ${ }^{88}$.

TITLE: The participation of the Autonomous Communities in the appointment of four constitutional judges by the senate.

ABSTRACT: This article analyses the participation of the Autonomous Communities in the appointment by Senate of four members of the Constitutional Court. With this

85 Nuevamente, AATC 387/2007, 443/2007, y 81/2008.

86 En tal sentido, de gran interés resulta el último ensayo de G. ZAGREBELSKY publicado en nuestro país y relativo a la condición de los Magistrados constitucionales en Italia: Principios y votos. El Tribunal Constitucional y la política, M. Martínez Neira (trad. del italiano), Trotta, Madrid, 2008.

87 A estos efectos, vid. G. CÁmARA VILLAR, Votos particulares y derechos fundamentales en la práctica del Tribunal Constitucional español (1981-1991), Ministerio de Justicia, Madrid, 1993.

88 En esta línea, I. Torres Muro, "La reforma de la Ley Orgánica del Tribunal Constitucional... cit., págs. $1-3$. 
aim, the author expounds the development of the legal context on this area until the amendments of the Organic Law on the Constitutional Court and the Standing Orders of Senate, which finally establish the participation of these subjects in the appointment, and considers the Constitutional Court Decisions 49/2008 and 101/2008, where it is resolved the constitutionality of both reforms. To conclude, the author makes a global consideration of the present legal context and values the situation of the Constitutional Court at the moment.

RESUMEN: Este trabajo analiza la participación de las Comunidades Autónomas en la elección de los cuatro magistrados constitucionales que corresponden al Senado. A tal fin, se presenta primeramente el proceso normativo que desemboca en las reformas de la Ley Orgánica del Tribunal Constitucional y del Reglamento del Senado que prevén tal participación, para seguidamente entrar en las Sentencias del Tribunal Constitucional 49/2008 y 101/2008, en las que se resuelve la constitucionalidad de ambas reformas. Finalmente, se concluye con una valoración global del marco normativo alcanzado, asi como sobre la situación en la que se encuentra el Tribunal Constitucional.

KEY WORDS: Constitutional Judges. Autonomous Communities. Senate. Organic Law of the Constitutional Court and Standing Orders of Senate.

Palabras Clave: Magistrado constitucional. Comunidad Autónoma. Senado. Ley Orgánica del Tribunal Constitucional y Reglamento del Senado. 